OPEN ACCESS

Edited by:

Saleh AlGhamdi,

King Saud bin Abdulaziz University

for Health Sciences, Saudi Arabia

Reviewed by:

Julie McAuley,

University of Melbourne - The Peter

Doherty Institute for Infection

and Immunity, Australia

Sergey P. Morzunov,

University of Nevada, Reno, USA

${ }^{*}$ Correspondence:

Hassan Zaraket

hassan.zaraket@aub.edu.lb

Specialty section:

This article was submitted to Infectious Diseases,

a section of the journal

Frontiers in Microbiology

Received: 14 January 2016 Accepted: 21 March 2016

Published: 31 March 2016

Citation:

Alame MM, Massaad E and Zaraket $H$ (2016) Peramivir: A Novel Intravenous Neuraminidase Inhibitor for Treatment of Acute Influenza Infections.

Front. Microbiol. 7:450

doi: 10.3389/fmicb.2016.00450

\section{Peramivir: A Novel Intravenous Neuraminidase Inhibitor for Treatment of Acute Influenza Infections}

\author{
Malak M. Alame' ${ }^{1}$ Elie Massaad ${ }^{2}$ and Hassan Zaraket ${ }^{2,3 *}$ \\ ${ }^{1}$ The School of Pharmacy, Lebanese International University, Beirut, Lebanon, ${ }^{2}$ Department of Experimental Pathology, \\ Immunology, and Microbiology, Faculty of Medicine, American University of Beirut, Beirut, Lebanon, ${ }^{3}$ Center for Infectious \\ Diseases Research, Faculty of Medicine, American University of Beirut, Beirut, Lebanon
}

Peramivir is a novel cyclopentane neuraminidase inhibitor of influenza virus. It was approved by the Food and Drug Administration in December 2014 for treatment of acute uncomplicated influenza in patients 18 years and older. For several months prior to approval, the drug was made clinically available under Emergency Use authorization during the $2009 \mathrm{H} 1 \mathrm{~N} 1$ influenza pandemic. Peramivir is highly effective against human influenza $A$ and $B$ isolates as well as emerging influenza virus strains with pandemic potential. Clinical trials demonstrated that the drug is well-tolerated in adult and pediatric populations. Adverse events are generally mild to moderate and similar in frequency to patients receiving placebo. Common side effects include gastrointestinal disorders and decreased neutrophil counts but are self-limiting. Peramivir is administered as a singledose via the intravenous route providing a valuable therapeutic alternative for critically ill patients or those unable to tolerate other administration routes. Successful clinical trials and post-marketing data in pediatric populations in Japan support the safety and efficacy of peramivir in this population where administration of other antivirals might not be feasible.

Keywords: influenza, neuraminidase inhibitors, peramivir, efficacy, safety

\section{INTRODUCTION}

Influenza virus infections cause significant morbidity and mortality during annual outbreaks and result in large economic losses due to healthcare costs and loss of productivity (Nicholson et al., 2003). These outbreaks occur during the winter season in countries with temperate weather and during rainy seasons in tropical countries (Tamerius et al., 2010). Influenza pandemics periodically occur due to the emergence of antigenically novel influenza viruses in humans and can pose a threat for higher morbidity and mortality rates than seasonal outbreaks (Salomon and Webster, 2009). In the last century four major pandemics have occurred: the Spanish influenza (1918), the Asian influenza (1957), the Hong Kong influenza (1968), and the 2009 H1N1 pandemic influenza (H1N1pdm09; Cox and Subbarao, 2000). Currently, several avian-origin influenza strains carry pandemic potential (Abdelwhab and Hafez, 2011; Tan et al., 2015). So far, influenza control efforts have focused on vaccines and antiviral therapies that target different components of the virus or host factors. 
Influenza viruses belong to the Orthomyxoviridae family with two types, $A$ and $B$, which are the cause of major outbreaks in humans. Influenza viruses have negative-sense, single-stranded, segmented RNA genomes and possess three membrane proteins, the hemagglutinin (HA), the neuraminidase (NA), and the matrix protein (M2; McGeoch et al., 1976; Palese and Schulman, 1976; Palese, 1977). The HA protein mediates sialic acid-conjugated cell receptor recognition, receptor binding, and fusion-mediated entry into cells (Sauter et al., 1992; Hamilton et al., 2012). The M2-channel (proton pump) facilitates release of viral RNA into the cytoplasm by acidifying the virus interior (de Vries et al., 2011). Virus replication commences in the nucleus and virus assembly occurs at the cell membrane (Leser and Lamb, 2005; Banerjee et al., 2013). The NA protein facilitates the release of newly assembled virus particles by cleavage of sialic acid residues (Colman, 1994). The NA also promotes virus movement through airway mucus thereby enhancing its infectivity (Yang et al., 2014).

Influenza A viruses are highly diverse with $16 \mathrm{HA}$ and $9 \mathrm{NA}$ subtypes identified thus far (Salomon and Webster, 2009). Wild aquatic birds are the main reservoir for influenza A viruses, which can also infect many other hosts, including humans (Webster et al., 1992). Furthermore, bats have recently been identified as the reservoir for two novel influenza-like subtypes (H17N9 and H18N10; Tong et al., 2012, 2013; Wu et al., 2014). Two influenza A subtypes (H1N1 and H3N2) and two influenza B strains (Yamagata and Victoria) are the major subtypes that cause annual outbreaks in humans (Nicholson et al., 2003). However, several avian influenza subtypes (e.g., H5N1, H7N9, and H9N2) have caused human infections and pose a pandemic threat should they adapt and acquire aerosol transmissibility among humans (Alexander et al., 2009; Abdelwhab and Hafez, 2011; Lam et al., 2015).

Influenza vaccines and antiviral drugs are effective in preventing infections or ameliorating disease severity (Osterholm et al., 2012). Live-attenuated and inactivated vaccines are available for prevention of influenza (Krammer and Palese, 2015). Two antiviral groups, M2 channel blockers and neuraminidase inhibitors (NAIs) are available for treatment and prevention of influenza infections (Jefferson et al., 2001; Stoll et al., 2003; Burnham et al., 2013). The emergence of high levels of M2 channel blocker resistance (Hata et al., 2007; Ison, 2011), have made NAIs the drugs of choice for prevention and treatment of influenza infections. Antivirals have an advantage over vaccines as they are readily available in case of the emergence of novel influenza viruses, for which the development of an effective vaccine would take several months (Wong and Webby, 2013). This was clearly demonstrated with the H1N1pdm09 emergence in 2009 during which the antiviral drug, oseltamivir, was heavily utilized while a vaccine was under development (Miller et al., 2013). Recently licensed by the Food and Drug Administration (FDA; McLaughlin et al., 2015), peramivir (BCX-1812 and RWJ-270201) is the latest addition to the already of approved NAIs, oseltamivir and zanamivir (Ison, 2011). Peramivir is administered intravenously providing an alternative access to patients unable to take medication via the oral (oseltamivir) or inhalation (zanamivir) routes. This review will focus on the development, efficacy, and safety of peramivir. In vitro and in vivo efficacies and pharmacokinetics data as well as emergence of resistance to antivirals will also be discussed.

\section{DESIGN AND MODE OF ACTION OF PERAMIVIR}

The active site of influenza virus NA enzyme is made up of 18 highly conserved residues (Colman, 1994). The catalytic site is made up of eight residues (R118, D151, R152, R224, E276, R292, R371, and Y406 in N2 numbering) that directly interact with the substrate (sialic acid) and participate in its catalysis. The framework site, made up of 11 residues (E119, R156, W178, S179, D/N198, I222, E227, H274, E277, N294, and E425), provides a structural framework support for the catalytic residues (Colman et al., 1983, 1993; Burmeister et al., 1992; Gubareva et al., 2001). Influenza A virus lacking the NA protein is able to infect cells but progeny viruses aggregate and fail to be released from the cell-surface (Liu et al., 1995). Similarly, blocking the enzymatic activity of the NA protein by NAIs results in the formation of virus aggregates and prevents the release of the virus from the cell surface (Palese and Compans, 1976). Elucidation of the structure and mechanism of action of the NA have made structure- and mechanism-based design of NAIs possible (Colman, 1994; Stoll et al., 2003; von Itzstein, 2007). These data have led to the identification of several potent NA inhibitors including three that have been approved for clinical use [peramivir (Babu et al., 2000), oseltamivir (Kim et al., 1997), and zanamivir (von Itzstein et al., 1993)] and one that is still under development [laninamivir (Yamashita et al., 2009), currently only approved in Japan; Table 1].

Peramivir was designed using crystallographic screening of enzyme-bound compounds containing a mixture of isomers to detect the most active isomer (Babu et al., 2000). It is a novel cyclopentane that is structurally distinct from other NAIs. It has a C4-guanidino substitution and a hydrophobic side chain, resembling zanamivir and oseltamivir, respectively, to take advantage of both hydrophilic pockets of the NA enzyme (Figures 1 and 2) (Kim et al., 1997; Babu et al., 2000; Malaisree et al., 2008). These substitutions allow tight interactions between peramivir and the enzyme active site. The negatively charged carboxylate group forms eight strong hydrogen bonds with a triad of conserved arginine residues (R118, R292, and R371) compared to only six bonds for oseltamivir and zanamivir. The methyl group of the acetamido occupies the hydrophobic pocket formed of residues W178 and I222, whereas the oxygen and nitrogen atoms form hydrogen bonds with Arg152 and a bound water molecule. The guanidino group fills the fourth pocket, forming stable hydrogen bonds and electrostatic interactions with the acidic groups of E119, D151, and E227 and replacing the existing water molecule in this pocket (Babu et al., 2000; Shetty and Peek, 2012). These interactions and the extra bonds formed between peramivir and its target, allow peramivir to tightly bind the NA active site and to have a slow dissociation-rate $\left(t_{1 / 2}>24 \mathrm{~h}\right)$ in comparison to oseltamivir and zanamivir $\left(t_{1 / 2}=1.25 \mathrm{~h}\right.$; Bantia et al., 2006). 
TABLE 1 | Neuraminidase inhibitors currently approved or undergoing clinical trials for treatment and prophylaxis against influenza.

\begin{tabular}{|c|c|c|c|c|c|c|c|}
\hline Drug & Code name & Chemical name & Brand name & Company & Route & Approval year & Reference $^{1}$ \\
\hline Oseltamivir & GS4104 & $\begin{array}{l}\text { ethyl (3R,4R,5S)-4-acetamido-5- } \\
\text { amino-3-pentan-3- } \\
\text { yloxycyclohexene-1- } \\
\text { carboxylate;phosphoric } \\
\text { acid }\end{array}$ & Tamiflu $^{\oplus}$ & Roche & Oral & 1999 & $\begin{array}{l}\text { Kim et al., } \\
1997\end{array}$ \\
\hline Zanamivir & $139110-80-8$ & $\begin{array}{l}\text { (2R,3R,4S)-3-acetamido-4- } \\
\text { (guanidino)-2-[(1R,2R)-1,2,3- } \\
\text { trihydroxypropyl]-3,4-dihydro-2H- } \\
\text { pyran-6-carboxylic } \\
\text { acid }\end{array}$ & Relenza ${ }^{\oplus}$ & GlaxoSmithKline & $\begin{array}{l}\text { Oral } \\
\text { inhalation }\end{array}$ & 1999 & $\begin{array}{l}\text { von Itzstein } \\
\text { et al., } 1993\end{array}$ \\
\hline Peramivir & $\begin{array}{l}\text { BCX-1812 and } \\
\text { RWJ-270201 }\end{array}$ & $\begin{array}{l}\text { (1S,2S,3S,4R)-3-[(1S)-1- } \\
\text { acetamido-2-ethylbutyl]-4- } \\
\text { (diaminomethylideneamino)-2- } \\
\text { hydroxycyclopentane-1-carboxylic } \\
\text { acid }\end{array}$ & Rapivab $^{\circledR}$ & BioCryst & Intravenous & 2014 & $\begin{array}{l}\text { Babu et al., } \\
2000\end{array}$ \\
\hline Laninamivir & $R-125489$ & $\begin{array}{l}\text { (2R,3R,4S)-3-acetamido-4- } \\
\text { (guanidino)-2-[(1R,2R)-2,3- } \\
\text { dihydroxy-1-methoxypropyl]-3,4- } \\
\text { dihydro-2H-pyran-6-carboxylic } \\
\text { acid }\end{array}$ & Inavir ${ }^{\circledR}$ & $\begin{array}{l}\text { Daiichi } \\
\text { Sankyo/Biota }\end{array}$ & $\begin{array}{l}\text { Oral } \\
\text { inhalation }\end{array}$ & $--^{2}$ & $\begin{array}{l}\text { Yamashita } \\
\text { et al., } 2009\end{array}$ \\
\hline
\end{tabular}

${ }^{1}$ Details on nomenclature and structure can be found at https://pubchem.ncbi.nlm.nih.gov

${ }^{2}$ Laninamivir was granted approval for clinical use in Japan in 2010 and is currently used in clinical practice.

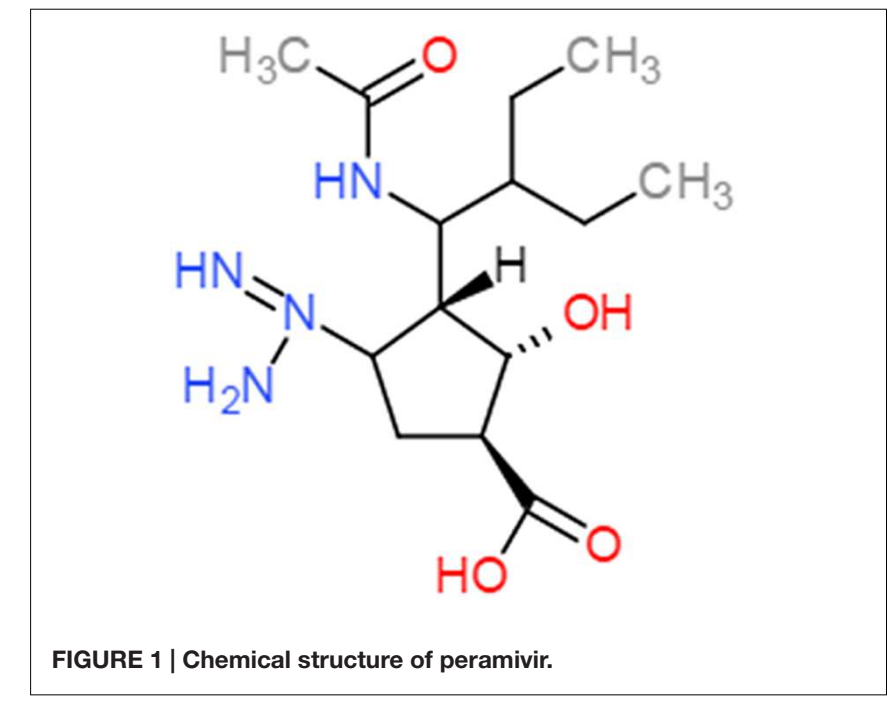

In vitro activity of peramivir has been investigated against human and avian influenza $\mathrm{A}$ and $\mathrm{B}$ viruses (Babu et al., 2000; Bantia et al., 2001; Govorkova et al., 2001; Gubareva et al., 2001; Ikematsu et al., 2014, 2015a,b; Leang et al., 2014; Zaraket et al., 2014). These studies have consistently shown that peramivir possesses comparable or superior inhibitory activity against influenza $\mathrm{A}$ and $\mathrm{B}$ viruses as oseltamivir, zanamivir, and laninamivir. Influenza $B$ isolates have been shown to be intrinsically less susceptible in vitro to oseltamivir compared to H1N1 and H3N2 viruses (Zaraket et al., 2010, 2014; Ikematsu et al., 2014, 2015a,b). Notably, peramivir shows improved in vitro activity against influenza $\mathrm{B}$ isolates compared to oseltamivir or zanamivir. The $\mathrm{IC}_{50}$ (50\% inhibitory concentration) values of peramivir against influenza $\mathrm{B}$ were reported to be several folds lower than those of the rest of the NAIs (Dapat et al., 2010; Ikematsu et al., 2014, 2015a,b; Zaraket et al., 2014). Importantly, peramivir has been also demonstrated to be highly effective in vitro against emerging avian influenza viruses of pandemic potential including $\mathrm{H} 5 \mathrm{~N} 1, \mathrm{H} 7 \mathrm{~N} 9$, and H9N2 (Govorkova et al., 2001; Zhang et al., 2014; Marjuki et al., 2015).

\section{OTHER INFLUENZA VIRUS INHIBITORS}

Aside from NA, at least four other viral targets have been identified for drug design based on their functions. These include the HA (Sauter et al., 1992; Mammen et al., 1995), the M2 (Hay et al., 1986), the polymerase (PB1, PB2, and PA; Hastings et al., 1996), and the NP (Tompkins et al., 2004) proteins. Furthermore, research focused on targeting host proteins and signaling pathways that play a role during influenza virus lifecycle is underway (Edinger et al., 2014).

Inhibitors targeting the HA protein can be divided into two groups based on their mode of action: (1) inhibitors directly targeting the HA protein, and (2) inhibitors indirectly targeting the HA protein (Li et al., 2015). The first group includes peptides and small molecules that interact with the HA molecule to inhibit the HA-mediated membrane fusion step (Jones et al., 2006; Zhu et al., 2011; Basu et al., 2014; White et al., 2015). It also contains molecules that bind to the HA protein disrupting its interaction with sialic acid receptors and preventing the virus from binding to the cell (Matsubara et al., 2010; Chen et al., 2015). This group also includes surfactant D and other collectins that bind to oligosaccharides on the HA molecules, hindering receptor binding (Hartshorn et al., 2008). The second group of HA inhibitors include molecules that inhibit host proteolytic enzymes (e.g., kallikrein-peptidases) necessary 


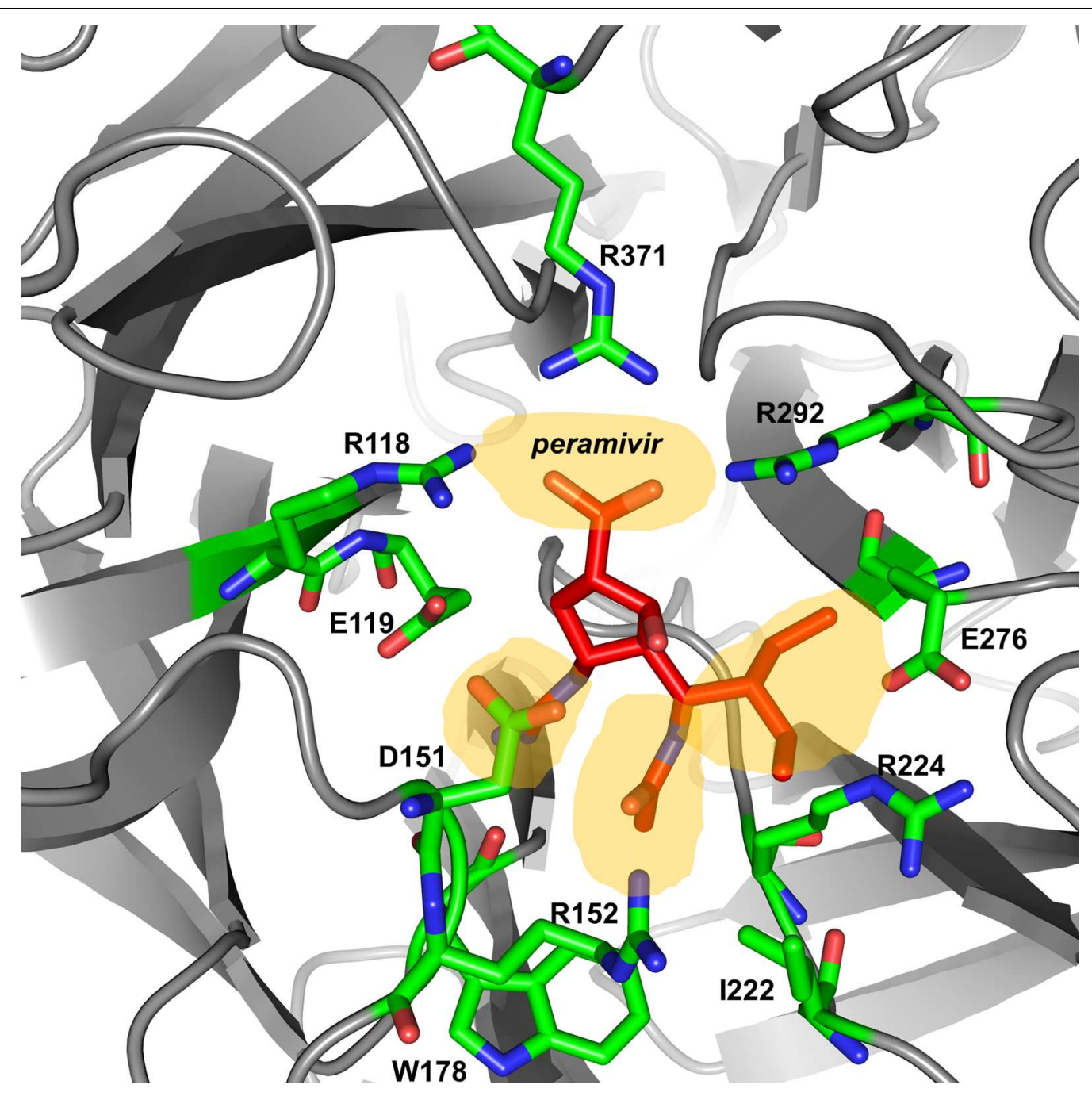

FIGURE 2 | Peramivir bound to influenza A/H7N9 neuraminidase. Crystal structure of peramivir and influenza A/H7N9 neuraminidase complex (4 MWV). The four binding pockets of the enzyme active site are shown in yellow shades.

for cleavage-activation of the $\mathrm{HA}$ protein or molecules that inhibit V-ATPase dependent endosomal acidification necessary for the HA fusion-activation step (Chen et al., 2013; Leu et al., 2015).

Attempts to develop new M2-channel blockers are underway; however, these compounds seem to be inactive against mutants resistant to existing M2 inhibitors (Balgi et al., 2013). Polymerase inhibitors are highly effective against influenza virus replication (DuBois et al., 2012; Furuta et al., 2013). The most prominent drug of this group is favipiravir (T-705), a purine analog inhibitor of the viral RNA polymerase (Furuta et al., 2005; Baranovich et al., 2013). Favipiravir holds promise not only as an influenza antiviral but also against many other RNA viruses (Furuta et al., 2013). NP inhibitors include short interfering RNAs targeting conserved regions of the NP gene (Tompkins et al., 2004) or small molecules that inhibit oligomerization and subsequent nuclear import of the NP protein (Semenova et al., 2010).
In addition to drugs targeting viral proteins, several therapeutics targeting host factors are under development. Hosttargeting drugs have the advantage of not selecting changes in the virus that could lead to resistance. Fludase (DAS18), a recombinant fusion protein composed of a sialidase catalytic domain derived from Actinomyces viscosus fused with a cell surface-anchoring sequence, cleaves sialic acid receptors from the airway epithelia, thus preventing virus attachment and infection (Malakhov et al., 2006). Nitazoxanide (NT-300), originally developed and licensed as antiprotozoal agent, is currently developed as a first-in-class broad-spectrum antiviral agent and is efficacious in reducing duration of influenza infection in Phase 2b/3 clinical trial (Haffizulla et al., 2014; Rossignol, 2014). Nitazoxanide inhibits influenza virus replication by blocking post-translational maturation of the viral HA protein (Rossignol et al., 2009). Despite the constant development of various influenza virus inhibitors, the rapid evolution of the virus makes resistance a compelling challenge. 


\section{DRUG RESISTANCE}

In 2007 and 2008, high levels of oseltamivir resistance among seasonal $\mathrm{H} 1 \mathrm{~N} 1$ viruses emerged worldwide undermining the efficacy of this drug. Nonetheless, post-pandemic 2009 influenza $A$ and B viruses remain largely susceptible to NAIs (Ikematsu et al., 2014, 2015b; Leang et al., 2014; Meijer et al., 2014; Takashita et al., 2014; Zaraket et al., 2014). The prevalence of peramivir-resistance among influenza A/H1N1pdm09 viruses ranges between 1.3 and $3.2 \%$ and is $<1 \%$ among influenza A/H3N2 and B viruses (Leang et al., 2014; Meijer et al., 2014; Takashita et al., 2014). Gubareva et al. (2001) have suggested that while resistant variants with mutations in the enzyme framework can retain susceptibility to other NAIs, those in the functional or catalytic residues tend to cause cross-resistance to all NAIs. Their study demonstrated that the most commonly detected H274Y (H275Y N1 numbering) framework mutation conferring resistance to oseltamivir results in cross-resistance to peramivir but not to zanamivir (Gubareva et al., 2001). This mutation has been shown to rapidly emerge upon intravenous (IV) treatment with peramivir in immunocompromised or hematopoietic cell transplant recipients (Memoli et al., 2010; Renaud et al., 2010). Nonetheless, in contrast to oral oseltamivir, the efficacy of peramivir against the H1N1 H274Y variant has been demonstrated in vivo upon single or multiple-intramuscular (IM) or IV regimens in mice, suggesting that peramivir could be used against oseltamivirresistant $\mathrm{H} 274 \mathrm{Y}$ influenza virus infections (Abed et al., 2011, 2012). Human influenza B isolates with H273Y mutation in the NA active site were found to be resistant to both oseltamivir and peramivir but not zanamivir (Higgins et al., 2012). Resistance to peramivir due to HA mutations has also been described in vitro (Smee et al., 2001). Serial passages of an H3N2 virus in the presence of peramivir caused selection of peramivirresistant viruses linked to a $\mathrm{K} 189 \mathrm{E}$ mutation in the HA protein.

The zanamivir-resistant influenza A/H3N2 variants with framework E119G or E119A mutations remain susceptible to peramivir and oseltamivir (Gubareva et al., 2001). Using reverse genetics, it was shown that these two mutations, as well as the E119D substitution, induce resistance to zanamivir but not to peramivir or oseltamivir in the H1N1pdm09 virus background (Baek et al., 2015). Surprisingly, laboratory generated H5N1 virus with the E119D mutation possessed high level of resistance to all NAIs. While the E119V mutation in the H3N2 context conferred resistance to oseltamivir only (Meijer et al., 2014). In influenza B, an $\mathrm{R} 152 \mathrm{~K}$ catalytic site mutation caused cross-resistance to all of the three NAIs (peramivir, oseltamivir, and zanamivir; Gubareva et al., 2001). In contrast, an H1N1pdm09 virus with this mutation remains sensitive to all three approved NAIs (Baek et al., 2015). Zanamivir-resistant influenza B R292K variant was found to be extremely resistant to oseltamivir but was moderately resistant to peramivir (Gubareva et al., 2001; Meijer et al., 2014).

Resistance to NAIs seems to arise easily among emerging influenza viruses as well. Itoh et al. (2015) reported the emergence of H7N9 influenza A virus with a R289K NA mutation conferring resistance to oseltamivir and peramivir upon NAI treatment in non-human primates. H7N9 viruses continue to cause human infections posing a pandemic threat (Zhu et al., 2016). The emergence of resistance among these viruses is a reason for concern.

Azuma et al. (2015) reported the presence of peramivir and laninamivir in high concentrations in sewage effluent and river waters in Japan. This could result in passive exposure of wild birds to these NAIs and give rise to the emergence of NAIresistance. This could be especially the case during pandemics which trigger high consumption levels of NAIs. Maintaining the efficacy of new and old antiviral drug inhibitors requires continuous monitoring of the susceptibility of circulating and emerging influenza viruses. Additionally, the ease and potential for emergence of NAI-resistant influenza viruses highlights the importance of assessing combination antiviral treatments for influenza (Govorkova and Webster, 2010). Combining antivirals targeting different influenza viral proteins and/or host molecules can hinder the emergence of resistance.

\section{PRECLINICAL STUDIES}

Numerous studies have demonstrated the efficacy of peramivir against human and emerging influenza viruses in vivo (Govorkova et al., 2001; Sidwell et al., 2001a; Sweet et al., 2002; Barroso et al., 2005; Bantia et al., 2006, 2011; Boltz et al., 2008; Abed et al., 2012). Earlier studies focused on assessing the oral efficacy of peramivir in comparison with oseltamivir and zanamivir treatment. Prophylactic peramivir treatment administered at a $10 \mathrm{mg}$ per/ $\mathrm{kg} /$ day by oral gavage twice daily for 5 days reduced lung viral load and provided complete protection against lethal challenge with $\mathrm{H} 5 \mathrm{~N} 1$ and H9N2 viruses in mice, similar to oseltamivir and consistent with the in vitro efficacies of these drugs (Govorkova et al., 2001). Similar levels of protection were demonstrated with prophylactic peramivir administration of $1-10 \mathrm{mg} / \mathrm{kg} /$ day twice daily for 5 days against $\mathrm{H} 1 \mathrm{~N} 1, \mathrm{H} 3 \mathrm{~N} 2$, and $\mathrm{H} 6 \mathrm{~N} 2$ viruses (Babu et al., 2000; Bantia et al., 2001; Sidwell et al., 2001a,b). Oral peramivir also significantly inhibited mortality in mice infected with influenza B virus (Sidwell et al., 2001b). Studies in ferrets suggested that 3- to 10-fold higher peramivir doses than those used in mice were needed to significantly reduce virus shedding in nasal washes and reduce inflammatory response in an H3N2 challenge model (Sweet et al., 2002). It remained unclear whether these differences were hostdependent or due to the different H3N2 strains used in each host.

Pharmacodynamics studies in mice demonstrated that the antiviral effect of peramivir was independent of the schedule used and recommended once-daily dosing as the basis for future drug evaluations (Drusano et al., 2001). Further studies showed that delayed oral administration of peramivir $48 \mathrm{~h}$ after $\mathrm{H} 5 \mathrm{~N} 1$ infection resulted in 50\% reduced mortality in mice (Govorkova et al., 2001). In contrast, Bantia et al. (2001) reported failure of delayed treatment of H6N2 infected mice at $48 \mathrm{~h}$ after infection and found that full protection required initiation of treatment at $24 \mathrm{~h}$ after infection. Another study found that oral 
treatment with peramivir could be delayed at least $60 \mathrm{~h}$ after virus exposure and still prevent mortality in $\mathrm{H} 1 \mathrm{~N} 1$ infected mice, however, administration at $24 \mathrm{~h}$ after exposure provided the greatest suppression of lung virus titers (Sidwell et al., 2001b). Delayed oral peramivir treatment was also shown to be effective in immunosuppressed mice infected with H1N1 virus (Sidwell et al., 2001a). These studies emphasize the importance of accurate diagnosis and early initiation of the treatment for optimal drug efficacy.

Despite the well-established efficacy of oral peramivir in animal studies, human clinical trials resulted in less success due to low oral bioavailability (Barroso et al., 2005). Thus, further efforts were focused on exploring the parenteral route. The first study investigating the IM route in mice infected with $\mathrm{H} 1 \mathrm{~N} 1$ or $\mathrm{H} 3 \mathrm{~N} 2$ viruses demonstrated that a single, prophylactic or delayed, $10-20 \mathrm{mg} / \mathrm{kg}$ dose significantly reduced morbidity (measured by weight loss) and mortality similar to the 5-day regimen of oral peramivir (Bantia et al., 2006). This efficacy was unmatched by IM-administered oseltamivir, which failed to provide any protection. Additionally, both prophylactic and delayed treatments with a single IM peramivir injection were effective against H1N1pdm09 infection in mice (Bantia et al., 2011).

In the case of a peramivir-resistant $\mathrm{H} 1 \mathrm{~N} 1$ virus with the H274Y mutation, multiple IM doses demonstrated superior efficacy in comparison to single IM dose regimens administered as a prophylaxis in a mouse challenge model (Abed et al., 2010). IM peramivir, single and multiple doses, prevented mortality in peramivir-resistant $\mathrm{H} 1 \mathrm{~N} 1$-infected mice when it was administered at 24 or $48 \mathrm{~h}$ post-infection (Abed et al., 2012). Nonetheless, mice receiving peramivir IM injection at $24 \mathrm{~h}$ post-infection exhibited less weight loss compared to when treatment was delayed by $48 \mathrm{~h}$. Post-exposure IM peramivir treatment also mitigated the disease and reduced the infectious virus titers promoting survival of mice infected with the highly pathogenic $\mathrm{H} 5 \mathrm{~N} 1$ influenza virus, although multiple doses were needed (Boltz et al., 2008; Yun et al., 2008). Contrary to the effectiveness of a single IM dose used to treat low pathogenic viruses like H1N1 (Bantia et al., 2006), a single IM injection of peramivir administered $1 \mathrm{~h}$ post-inoculation with a lethal $\mathrm{H} 5 \mathrm{~N} 1$ virus resulted in only 33\% survival in mice (Boltz et al., 2008). Survival improved to $55 \%$ with two IM peramivir doses. An 8-day regimen consisting of two daily IM injections starting $1 \mathrm{~h}$ post-exposure followed by seven daily IM doses provided mice with $100 \%$ protection from lethal $\mathrm{H} 5 \mathrm{~N} 1$ challenge, but survival decreased to 78 and $56 \%$ when treatment was delayed by 24 and $48 \mathrm{~h}$, respectively (Boltz et al., 2008). The 8-day regimen of $30 \mathrm{mg} / \mathrm{kg} /$ day IM peramivir, with the first dose initiated at the time of infection, also resulted in reduction of lung virus titers and mortality in mice infected with a lethal dose of the H7N9 virus (Farooqui et al., 2015).

Combination regimens of IM peramivir with oseltamivir or amantadine performed better than peramivir monotherapy against H1N1 and H3N2 viruses (Bantia et al., 2010; Smee et al., 2010). In addition, IM peramivir treatment coupled with oral favipiravir was more effective and a reduced dose was needed than in monotherapy against peramivir-resistant H1N1pdm09 virus (Park et al., 2014). Nonetheless, in the aforementioned studies, a 5-day regimen was used to test the combination therapy (Bantia et al., 2010; Smee et al., 2010; Park et al., 2014). Therefore, further research is needed to elucidate the effect of the approved single-dose treatment of peramivir in combination with other antiviral drugs.

Consistent with the effectiveness of the IM regimen, multiple studies demonstrated the efficacy of single IV injection of peramivir in animal models (Kitano et al., 2011; Kakuta et al., 2013). A single IV administration of $30 \mathrm{mg} / \mathrm{kg}$ peramivir resulted in significant reduction of nasal virus titers and clinical symptoms in ferrets and cynomolgus macaques infected with a recent influenza B virus strain, even when treatment was delayed up to $48 \mathrm{~h}$ post-infection (Kitano et al., 2011). IV peramivir administered as a single-dose of $30 \mathrm{mg} / \mathrm{kg}$ and $13 \mathrm{~h}$ after infection of mice with influenza $\mathrm{A} / \mathrm{H} 1 \mathrm{~N} 1$ or $\mathrm{B}$ viruses showed significant reduction in mortality and lung viral loads, an effect that was similar to laninamivir (Kakuta et al., 2013). Immunosuppressed mice infected with the H1N1pdm09 virus required 10-20 days of daily IV peramivir to attain $>80 \%$ survival, whereas a single-dose regimen was non-efficacious (Kitano et al., 2013). By contrast, repeated oral administration of oseltamivir $(5 \mathrm{mg} / \mathrm{kg}$ twice daily for 20 days) failed to show any improvement in survival of infected immunosuppressed mice despite significantly reducing weight loss.

Repeated IV administration of peramivir over 5 days starting on the day of infection or $24 \mathrm{~h}$ after infection significantly reduced viral titers, inflammatory cytokines, and the period to virus clearance in the upper respiratory tract of cynomolgus macaques infected with H5N1 virus (Kitano et al., 2014).

Single and repeated IV peramivir administration was also shown to inhibit virus replication and proinflammatory immune responses in mice co-infected with $\mathrm{H} 1 \mathrm{~N} 1 \mathrm{pdm} 09$ virus and the bacterium Streptococcus pneumonia, consequently leading to earlier bacterial clearance and significantly improved survival (Onishi et al., 2015; Tanaka et al., 2015). Outcomes of bacterial superinfection were significantly improved after a multipledose regimen of IV peramivir compared to single-dose IV peramivir or multiple oral doses of oseltamivir. Initiating treatment just after viral infection resulted in better outcomes than delaying treatment even if treatment was started before bacterial superinfection (Onishi et al., 2015). Therefore, quickly beginning peramivir administration after symptoms onset is important not only to resolve influenza virus infection, but also to prevent complications due to a subsequent bacterial infection.

Overall, animal experiments demonstrated that peramivir is as effective and in some cases more effective than other NAIs. Its safety profile in animal models and the efficacy of the singledose regimen makes it an attractive treatment choice for influenza infections.

\section{CLINICAL STUDIES}

\section{Pharmacokinetics}

Experimental clinical data revealed that oral peramivir is rapidly absorbed with plasma levels beginning to rise within $1 \mathrm{~h}$ of 
administration, and the maximum concentration $\left(\mathrm{C}_{\max }\right)$ being achieved in $2.5 \mathrm{~h}$ (range: 2-4 h; Young et al., 2001; Barroso et al., 2005). However, oral peramivir formulation showed low bioavailability $(\leq 3 \%)$ in humans despite the use of relatively high doses. Peak plasma levels were $\sim 100 \mathrm{ng} / \mathrm{ml}$ and $\sim 200 \mathrm{ng} / \mathrm{ml}$ after four doses of 400 and $800 \mathrm{mg}$ oral peramivir, respectively (Barroso et al., 2005). This warranted the study of parenteral formulations which resulted in high drug concentrations in the blood (Boltz et al., 2008). The peak plasma concentrations for IM and IV peramivir (10,000-20,000 ng/mL) are nearly two orders of magnitude higher than those achieved with standard doses of oral oseltamivir (Hayden, 2009; Kohno et al., 2010).

The pharmacokinetics (PK) of IV peramivir were evaluated in Phase I trials in adults (Food and Drug Administration, 2015b). These trials demonstrated a linear relationship between dose and drug exposure parameters (area under the curve [AUC] and $C_{\max }$; Mancuso et al., 2010; Food and Drug Administration, 2015b). Plasma concentrations of IV peramivir peaked immediately after administration (Whitley et al., 2014; Yoshino et al., 2015). At the end of a $30 \mathrm{~min}$ IV infusion of a single-dose of $600 \mathrm{mg}$ peramivir, $C_{\max }$ reached 46,800 $\mathrm{ng} / \mathrm{mL}$ and AUC was 102,700 $\mathrm{h} \times \mathrm{ng} / \mathrm{mL}$ (Food and Drug Administration, 2015b). Kohno et al. (2011a) assessed median plasma concentrations upon IV administration of single 300 or $600 \mathrm{mg}$ doses over a period of 15-60 min to high-risk patients (poorly controlled diabetes, chronic respiratory tract disease, and drug-induced immunosuppression). The median plasma concentration immediately before the end of the infusion was $25,500 \mathrm{ng} / \mathrm{mL}$ in the $300 \mathrm{mg}$ group and $51,500 \mathrm{ng} / \mathrm{mL}$ in the $600 \mathrm{mg}$ group. Moreover, 3-9\% of peramivir was detected in the nasal cavity and pharyngeal mucus of healthy subjects upon IV administration of $600 \mathrm{mg}$ dose. The drug concentration in pharyngeal mucus was $5,280 \mathrm{nM}$ at $2 \mathrm{~h}$ and $220 \mathrm{nM}$ at $12 \mathrm{~h}$ after administration, well above its $\mathrm{IC}_{50}$ values (Kohno et al., 2011a). Based on a population pharmacokinetic analysis, the central volume of distribution was $12.56 \mathrm{~L}$ (Food and Drug Administration, 2015b).

Despite a low in vitro plasma protein binding of less than 30\% (Chairat et al., 2013; Food and Drug Administration, 2015b), the elimination half-life of peramivir following a single IV administration of $600 \mathrm{mg}$ to healthy subjects is approximately 20 h (Boltz et al., 2008; Hayden, 2009; Ison et al., 2013; Food and Drug Administration, 2015b). Together with the slow NA dissociation rate (Bantia et al., 2006), the prolonged half-life allows for infrequent dosing regimens.

Peramivir is not significantly metabolized by the liver in humans. The drug is not a substrate for CYP enzymes, does not affect glucuronidation, and is not a substrate or inhibitor of $P$-glycoprotein mediated transport (Food and Drug Administration, 2015b). Thus, dose adjustment is unnecessary in hepatic impairment (Chairat et al., 2013).

Peramivir is almost entirely eliminated by renal excretion with $90 \%$ of the drug excreted unchanged (Mancuso et al., 2010; Chairat et al., 2013; Food and Drug Administration, 2015b). Negligible accumulation was observed following multiple doses, either once or twice daily for up to 10 days (Food and Drug Administration, 2015b). Clearance of peramivir is similar to the average creatinine clearance $(\mathrm{CrCl})$ for a $70 \mathrm{~kg}$ adult with normal renal function (Clay et al., 2011). This suggests that peramivir is excreted mainly by glomerular filtration. Moreover, $\mathrm{CrCl}$ was found to be the most important factor affecting peramivir PKs (Matsuo et al., 2015). Data from six clinical studies in Japan and the United States including healthy volunteers and influenza patients revealed that peramivir clearance was linearly related to $\mathrm{CrCl}$ when $\mathrm{CrCl}$ values were below $115 \mathrm{ml} / \mathrm{min}$. On the other hand, peramivir clearance was independent of $\mathrm{CrCl}$ when $\mathrm{CrCl}$ values were over $115 \mathrm{ml} / \mathrm{min}$ (Matsuo et al., 2015). No difference in PK was observed by gender, and the effects of age and body weight on peramivir clearance were negligible (Food and Drug Administration, 2015b; Matsuo et al., 2015). Peramivir clearance was $18 \%$ higher and its distribution volume was $6 \%$ lower in influenza patients compared to healthy volunteers. However, these differences are not considered clinically significant (Matsuo et al., 2015).

Additionally, the AUC of peramivir is highly dependent on $\mathrm{CrCl}$ (Matsuo et al., 2015). In patients with moderate and severe renal impairment exposure to peramivir upon IV administration is expected to be increased by 3.4- and 6-fold, respectively, compared to those with normal renal function (Chairat et al., 2013). Therefore, dose adjustment based on renal function in patients with renal impairment is required to provide AUCs comparable to those in patients with normal renal function (Table 2) (Chairat et al., 2013; Food and Drug Administration, 2015b; Matsuo et al., 2015). Using doses as high as $600 \mathrm{mg}$ IV once daily in patients with acute renal failure did not cause any toxicity suggesting a high clearance of peramivir by continuous renal replacement therapy (CRRT; Hernandez et al., 2011). Accordingly, peramivir dose should be adjusted based on the type and duration of CRRT provided. In a case report of an 18-yearold male, peramivir was well cleared by continuous venovenous hemofiltration with a half-life of 6.2 h (Scheetz et al., 2011). Peramivir was also shown to be removed by hemodialysis, with a 4 -h hemodialysis reducing the systemic peramivir exposure by $73-81 \%$ (Chairat et al., 2013). In patients with chronic renal impairment maintained on hemodialysis, peramivir should be administered after dialysis at a dose adjusted based on renal function (Food and Drug Administration, 2015b).

TABLE 2 | Dosage adjustment for patients with altered creatinine clearance.

\begin{tabular}{lccc}
\hline Renal function & Mild renal impairment & Moderate renal impairment & Severe renal impairment \\
\hline Creatinine clearance $(\mathrm{mL} / \mathrm{min})$ & $\geq 50$ & $30-49$ & $10-29$ \\
Recommended dose $(\mathrm{mg})$ & 600 & 200 & 100 \\
\hline
\end{tabular}

Source: Food and Drug Administration, 2015b. 
Two studies were conducted to evaluate PK interactions between IV peramivir and other influenza antivirals (Atiee et al., 2012). Concomitant administration of peramivir with oral oseltamivir or rimantadine in humans did not adversely affect their PK profile, demonstrating a lack of drug interaction.

\section{Efficacy}

Data from a double-blind, randomized, placebo-controlled study evaluating oral peramivir administration in experimentally infected influenza A or B patients, revealed a more pronounced drop in virus titers, regardless of virus type, in the peramivirtreated group compared to placebo (Iyer et al., 2002). These data mirrored the success of oral peramivir for treatment and prophylaxis of influenza infection in early animal studies (Bantia et al., 2001; Sidwell et al., 2001a; Sweet et al., 2002). Driven by the success of these studies, a phase III, double-blind, randomized, placebo-controlled study examined the efficacy of oral peramivir in treatment and prophylaxis of influenza $\mathrm{A} / \mathrm{H} 1 \mathrm{~N} 1$ and $\mathrm{B}$ infections (Barroso et al., 2005). In the prophylaxis arm, oral peramivir was administered $24 \mathrm{~h}$ prior to virus inoculation and continued for a total of 5 days. Only modest, non-significant reductions in virus shedding were observed across all study arms: $58 \%$ for placebo vs. 61,37 , and $31 \%$ for influenza A with 50, 100, and $200 \mathrm{mg}$ q.d. (once daily) regimens, respectively; $55 \%$ for placebo vs. 31,45 , and $47 \%$ for influenza B with 200, 400, and $800 \mathrm{mg}$ q.d. regimens, respectively (Barroso et al., 2005). These values were in sharp contrast with those for prophylactic oral oseltamivir regimens of $100 \mathrm{mg}$ q.d. or b.i.d. (twice daily), which completely prevented influenza A virus shedding (Hayden et al., 1999). When peramivir was administered orally $24 \mathrm{~h}$ after virus inoculation and continued for a total of 5 days, significant reductions in influenza $A$ and $B$ virus shedding rates were observed in treatment groups compared with placebo (Barroso et al., 2005). However, this effect was dose-dependent and was only observed with higher doses. The group concluded that despite peramivir tolerability, the lack of more robust antiviral effect is likely due to the relatively low oral bioavailability $(<3 \%)$ compared to oseltamivir $(80 \%)$ and recommended exploring alternative formulations or parenteral administration.

Intramuscular peramivir was tested in two double-blind, placebo-controlled studies in adult outpatients with acute, uncomplicated influenza (Whitley et al., 2014). In the first phase II clinical trial, 344 influenza patients were randomized to three treatment groups: single-dose peramivir $150 \mathrm{mg}$, peramivir $300 \mathrm{mg}$, and placebo. In the phase III clinical trial, 83 influenza patients were randomized to single-dose peramivir $300 \mathrm{mg}$ and placebo treatment groups. The phase III study was terminated early to focus on evaluating more concentrated formulations of peramivir. In both studies, peramivir was administered within $\leq 36 \mathrm{~h}$ of symptoms onset in $66-71 \%$ of participants who were dominantly infected by $\mathrm{H} 1 \mathrm{~N} 1$ or $\mathrm{H} 3 \mathrm{~N} 2$ (Whitley et al., 2014). An integrated analysis from both studies revealed that a single-IM peramivir dose significantly shortened the time to alleviation of symptoms (113.2 $\mathrm{h}$ for peramivir $300 \mathrm{mg}$ ) compared to placebo (134.8 h); a difference of $20.7 \mathrm{~h}$, adjusted $p=0.047$. For peramivir $150 \mathrm{mg}$, the difference was $21.6 \mathrm{~h}$.
Similar reductions in the time to defervescence and resumption of usual activities were reported with peramivir $300 \mathrm{mg}$ compared to placebo (Whitley et al., 2014). Subjects receiving 150 or $300 \mathrm{mg}$ peramivir exhibited significantly lower proportions of virus shedding on days 2 and 3 and lower virus titers on day 3 compared to placebo. An improvement in the time to alleviation of symptoms in patients treated with 150 or $300 \mathrm{mg}$ peramivir was associated with a significant increase in creatine kinase levels, a marker of successful IM administration (Shetty and Peek, 2012). Thus, a follow-up phase II study was conducted to evaluate to $600 \mathrm{mg}$ peramivir administered as bilateral 2-mL IM injections using longer needles (BioCryst Pharmaceuticals, 2015). A total of 405 subjects with confirmed influenza infections were randomized to receive placebo or $600 \mathrm{mg}$ peramivir IM. The time to alleviation of symptoms did not differ significantly between placebo $(106.9 \mathrm{~h})$ and $600 \mathrm{mg}$ peramivir (91.1 h; $p=0.22$ ). The failure of treatment was attributed to high prevalence of influenza A/H1N1 with $\mathrm{H} 274 \mathrm{Y}$ mutation conferring resistance to peramivir among the study subjects (BioCryst Pharmaceuticals, 2015). Thus, a single-IM peramivir administration failed to overcome resistance due the H274Y mutation. Based on animal studies (Abed et al., 2011, 2012), multiple doses might be necessary to treat patients infected with resistant viruses.

Several studies investigated the effect of IV peramivir as single- or multiple-doses for treatment of influenza infection (Kohno et al., 2010, 2011b; Ison, 2011; de Jong et al., 2014). A phase II clinical trial evaluated the efficacy of single-dose IV peramivir in previously healthy adults with confirmed influenza infection (predominantly seasonal H1N1; Kohno et al., 2010). Participants $(n=296)$ were randomized to receive $300 \mathrm{mg}$ peramivir, $600 \mathrm{mg}$ peramivir or placebo within $48 \mathrm{~h}$ of symptoms onset. IV peramivir 300 and $600 \mathrm{mg}$ doses significantly reduced time to alleviation of symptoms compared to placebo $(300 \mathrm{mg}$ $59.1 \mathrm{~h}, 600 \mathrm{mg} 59.9 \mathrm{~h}$, placebo $81.8 \mathrm{~h}$; adjusted $p$-values $=0.0092$ and 0.0092, respectively; Kohno et al., 2010). Defervescence was evident as early as $24 \mathrm{~h}$ after treatment. The proportions of subjects shedding virus were significantly smaller in the treatment groups (300 mg 36.8\% and $600 \mathrm{mg} \mathrm{35.8 \% )} \mathrm{compared} \mathrm{to} \mathrm{placebo}$ (51.5\%; $p$-values $=0.00485$ and 0.0003 , respectively; Kohno et al., 2010).

A multinational, multicenter, phase III study enrolled 1091 subjects in Korea, Japan, and Taiwan (Kohno et al., 2011b). The study compared single IV dose of peramivir (300 mg or $600 \mathrm{mg}$ ) to 5-day oral peramivir regimen (75 mg b.i.d.). Overall, the time to alleviation of symptoms was similar across all study groups: $300 \mathrm{mg}$ peramivir, $78.0 \mathrm{~h}$; $600 \mathrm{mg}$ peramivir, $81.0 \mathrm{~h}$; and oseltamivir, $81.8 \mathrm{~h}$. Despite the detection of the H274Y mutation among nearly $100 \%$ of patients infected with H1N1 (Kohno et al., 2011b), the time to alleviation of symptoms in the oseltamivir group was well within the range reported in previous years when oseltamivir-susceptible H1N1 was circulating (Nicholson et al., 2000; Treanor et al., 2000). The authors concluded that the significance of the study was not compromised due to the lack of a placebo group, and that the efficacy of oseltamivir was maintained despite the prevalence of the H274Y viruses (Kohno et al., 2011b). In the H3N2-infected subgroup of patients, 
peramivir (300 and $600 \mathrm{mg}$ doses) was as effective as oseltamivir. Surprisingly, the $300 \mathrm{mg}$ but not $600 \mathrm{mg}$ peramivir dose resulted in significantly shorter time to alleviation of symptoms compared to oseltamivir in the influenza B subgroup (55.3, 92.8, and $92.7 \mathrm{~h}$, respectively; Kohno et al., 2011b). A smaller scale study including 32 patients hospitalized for influenza A infections in 2012 also found no significant difference in the time to defervescence between peramivir and oseltamivir groups (Yoshino et al., 2015).

Further studies assessed the efficacy of multiple doses of peramivir in severely ill or hospitalized patients. In a phase II study, Ison et al. (2013) enrolled 122 hospitalized influenza patients who were randomized to receive IV 200 or $400 \mathrm{mg}$ peramivir q.d. or oral $75 \mathrm{mg}$ oseltamivir b.i.d. for 5 days. The study found no significant difference in the time to clinical stability among the three treatment groups: $200 \mathrm{mg}$ peramivir, $23.7 \mathrm{~h} ; 400 \mathrm{mg}$ peramivir, $37.0 \mathrm{~h}$; and oseltamivir, $28.1 \mathrm{~h}$. A post hoc analysis of clinical outcome of clinically unstable patients ( $n=97$ ) revealed similar findings (Ison et al., 2013). Consistent with earlier findings, a retrospective analysis of severely ill patients with influenza found IV peramivir to be as effective as oral oseltamivir treatment (Yoo et al., 2015). A phase III, open-label, multinational, clinical trial was conducted during the H1N1pdm09 to assess the antiviral activity of two dosing regimens of IV peramivir (300 $\mathrm{mg}$ b.i.d. or $600 \mathrm{mg}$ q.d. for 5 days; Ison et al., 2014). The median time to resolution of symptoms was $45 \mathrm{~h}$ for $300 \mathrm{mg}$ peramivir $(n=57)$ and $166 \mathrm{~h}$ for $600 \mathrm{mg}$ peramivir $(n=70)$. Nonetheless, it was noted that the $600 \mathrm{mg}$ group had more patients with severe disease (i.e., baseline need for ICU admission, need for supplemental oxygen, or high APACHE score), which might have attributed to the longer time to symptoms relief. No significant difference in the time-weighted change in virus titer from baseline to $48 \mathrm{~h}$ was observed between the treatment groups (Ison et al., 2014).

In high risk patients, defined as those with $\geq 1$ risk factors and $\geq 2$ moderate to severe influenza symptoms; $n=37$ ), single-dose IV peramivir (300 or $600 \mathrm{mg}$ ) was assessed with additional administrations delivered as needed up to 5 days (Kohno et al., 2011a). The median time to alleviation of illness was significantly longer for the $300 \mathrm{mg}$ peramivir $(114.4 \mathrm{~h}$ ) compared to the $600 \mathrm{mg}$ dose $(42.3 \mathrm{~h})$. Another phase III double-blind, randomized clinical trial, assessed the efficacy of multi-dose peramivir in hospitalized patients (de Jong et al., 2014). Of 1600 subjects screened, 338 subjects with confirmed influenza (A or B) were included in the intent to treat influenza (ITTI) population. Patients were randomized to receive placebo or $600 \mathrm{mg}$ IV peramivir q.d. for 5 days, in addition to the institution's standard of care (SOC) treatment. The non-NAI SOC ITTI (did not receive concurrent NAI) population included 121 patients and the remaining 217 belonged to the NAI SOC (216 received oseltamivir and 1 received zanamivir) ITTI population (de Jong et al., 2014). The median time to clinical resolution did not differ significantly between peramivir and placebo (42.5 h vs. $49.5 \mathrm{~h}$, respectively; $p=0.97$ ) in the nonNAI SOC population. Similar data were observed for the NAI SOC population. An improved treatment outcome was observed in subjects enrolled within $<48 \mathrm{~h}$ or those admitted to intensive care unit (ICU). However, the difference in time to clinical resolution between placebo and peramivir groups did not reach statistical significance due to the limited sample size and the study was terminated (de Jong et al., 2014). With the exception of this study, studies in severely ill patients are undermined by the lack of a placebo group, which is not possible in high risk populations.

Currently, IV peramivir is approved for use in children $<18$-year-old in Japan. The approval of peramivir in Japan was based on a multicenter, open-label, uncontrolled clinical study demonstrating efficacy and safety of IV peramivir in children (Sugaya et al., 2012). Children with confirmed influenza infection during the H1N1pdm09 and ranging in age between $\geq 28$ days to $<16$ years were enrolled. Peramivir was administered as IV infusion at $10 \mathrm{mg} / \mathrm{kg}$ (600 $\mathrm{mg}$ maximum dose in children with $\geq 60 \mathrm{~kg}$ body weight). The median time to alleviation of symptoms was $29.1 \mathrm{~h}$ and virus shedding was confirmed in 78.2 and $7.1 \%$ of children on days 2 and 6 after initiation of treatment, respectively (Sugaya et al., 2012). Hikita et al. (2012) compared the efficacy of IV peramivir (10 mg/kg, $\max 300 \mathrm{mg}$ per dose) with other NAIs. For influenza A patients, the median duration of fever was 1 day for peramivir and 2 days for zanamivir $(p=0.0242)$. In the case of influenza $B$, the median duration of fever was also 1 day for peramivir compared to 3 days for laninamivir $(p=0.0097)$. These results suggest that peramivir is also useful in children, especially where the use of inhalation drugs is not feasible.

\section{Safety}

Overall, peramivir demonstrated good tolerability and safety in all clinical studies (Kohno et al., 2010, 2011b; Ison et al., 2013, 2014; Whitley et al., 2014). Post-marketing evaluation of peramivir under routine clinical settings mirrored the clinical trials in terms of safety and effectiveness in adults and pediatrics (Komeda et al., 2014, 2015). Most reported adverse events (AEs) were mild to moderate in severity and were more common in young children (Kohno et al., 2011a; Sugaya et al., 2012; de Jong et al., 2014; Ison et al., 2014; Whitley et al., 2014) and their frequency was comparable to placebo (Kohno et al., 2010; Whitley et al., 2014). Peramivir AEs were similar in severity and frequency to those reported for oral oseltamivir (Kohno et al., 2011a; Ison et al., 2013), and generally occurred within 3 days of initiating treatment and rapidly subsided (Sugaya et al., 2012). The frequency of AEs was similar regardless of the number of doses received.

The most common AEs were gastrointestinal disorders including diarrhea (mild to moderate), nausea, and vomiting (Kohno et al., 2011a; Sugaya et al., 2012; Ison et al., 2013; de Jong et al., 2014; Komeda et al., 2014, 2015; Whitley et al., 2014). Komeda et al. (2015) reported that abnormal behavior, cough, and pyrexia were among the common AEs in pediatrics along with GI disorders. The majority of serious AEs were found to be related to influenza infection (e.g., pneumonia, chronic obstructive pulmonary disorder; de Jong et al., 2014). The most 
common severe AEs were decrease in neutrophil count (lowest mainly on day 3) and prolonged QT interval; however, these returned to normal without any intervention (Kohno et al., 2010, 2011a; Sugaya et al., 2012; Komeda et al., 2014, 2015).

Some rare but severe AEs were also reported upon treatment with peramivir. A 44-year-old man with history of lower than normal platelet count had severe thrombocytopenia that was possibly elicited by peramivir (Harada-Shirado et al., 2014). This was confirmed by druginduced lymphocyte-stimulating test which was positive for peramivir. Hayashi et al. (2015) described a case of exacerbated myasthenia gravis in a 73-year-old women triggered by IV peramivir.

\section{FDA APPROVAL}

Given its well-established efficacy and safety, the FDA granted approval for IV peramivir under the brand name Rapivab ${ }^{\mathrm{TM}}$ on December 19, 2014 (Food and Drug Administration, 2015b). Under the FDA approval, peramivir is indicated for treatment of acute uncomplicated influenza in patients 18 years and older who have been symptomatic for no more than 2 days. The recommended dose is $600 \mathrm{mg}$ administered once via IV infusion for 15-30 min within $48 \mathrm{~h}$ of symptoms onset. Peramivir must be diluted prior to administration. In case of renal impairment, the recommended dose is lowered to $200 \mathrm{mg}$ for patients with creatinine clearance $30-49 \mathrm{~mL} / \mathrm{min}$ and to $100 \mathrm{mg}$ for patients with creatinine clearance $10-29 \mathrm{~mL} / \mathrm{min}$ (Table 2).

\section{EMERGENCY USE AUTHORIZATION}

On October 23, 2009 upon request from the Centers for Disease Control and Prevention (CDC), the FDA issued an emergency use authorization (EUA) for IV peramivir while still an investigational antiviral drug, in hospitalized patients with H1N1pdm09 infection (Food and Drug Administration, 2015a). IV peramivir could only be used for hospitalized adult and pediatric patients who were not responsive to approved antivirals, or where delivery by alternative route (oral or inhaled) was not feasible. The EUA was effective through June 23, 2010. During this period, the CDC received 1371 requests for IV peramivir and 1274 hospitalized patients received $\geq 1$ dose (median duration $=6$ days; $\mathrm{Yu}$ et al., 2012). Under the EUA all AEs were to be reported to the FDA. Sorbello et al. (2012) reviewed $344 \mathrm{AE}$ reports to evaluate the safety of IV peramivir treatment in hospitalized patients under the EUA. Many of the patients were severely ill requiring mechanical ventilation and/or renal replacement therapy. The most commonly reported AEs were death $(18 \%)$, respiratory failure $(8 \%)$, acute renal failure (7\%), and acute respiratory distress syndrome (7\%). But these AEs were not considered to be caused by IV peramivir and were thought to be a direct outcome of influenza infection induced illnesses. Death was mainly associated with other risk factors (i.e., obesity, immunosuppressed, or aged >65 years; Sorbello et al., 2012). Rash was the only $\mathrm{AE}$ attributed to peramivir and was reported in 13 cases. Hernandez et al. (2011) reviewed data for 31 adult (including pregnant women) and pediatric hospitalized patients with severe H1N1pdm09 viral pneumonia who received IV peramivir during the EUA (Hernandez et al., 2011). The study concluded that the drug was generally well tolerated and associated with complete recovery.

A survey of the public acceptance of peramivir use under the EUA revealed that $48 \%$ of the participants would probably or definitely take peramivir (Quinn et al., 2015). Seventynine percent indicated that they would definitely take it if recommended by their physician or no alternative treatments were available. Willingness to take peramivir increased with increased illness severity and was also affected by the individual's trust in government actions (Quinn et al., 2015). Therefore, providing patients with relevant information on efficacy and safety of peramivir as well as potential risk of influenza complications is likely to improve patients' acceptance of treatment.

\section{CONCLUSION}

Peramivir is a highly potent inhibitor against influenza A and B viruses with a well-demonstrated safety profile. Administration via IV route provides an alternative for patients who cannot use oral drugs. Common side effects include gastrointestinal disorders and decreased neutrophil count and are self-limiting. While currently only approved for treatment of uncomplicated influenza in adults, clinical studies and post-marketing efficacy and safety data in pediatric populations provide promise for the potential of approval of peramivir in this highly susceptible population. The potential for emergence of resistant viruses and cross-resistance with oseltamivir remains a challenge for clinical practice. This highlights the need for continual development of antivirals targeting other influenza virus or host proteins while monitoring the effectiveness of existing drugs.

\section{AUTHOR CONTRIBUTIONS}

MA and HZ drafted the manuscript. EM helped summarizing literature for clinical studies and drug design. HZ edited the final draft.

\section{ACKNOWLEDGMENTS}

We thank Leen Masri for her assistance with the review and Samar Abedrabbo for her helpful suggestions. We are also thankful for Crystal W Burke for critically reviewing the manuscript. 


\section{REFERENCES}

Abdelwhab, E. M., and Hafez, H. M. (2011). An overview of the epidemic of highly pathogenic $\mathrm{H} 5 \mathrm{~N} 1$ avian influenza virus in Egypt: epidemiology and control challenges. Epidemiol. Infect. 139, 647-657. doi: 10.1017/S0950268810003122

Abed, Y., Boivin, G., Yoshida, R., Kodama, M., and Hernandez, J. E. (2011). Parenteral peramivir treatment for oseltamivir-resistant 2009 pandemic influenza A H1N1 viruses. J. Infect. Dis. 204, 1641-1642. doi: 10.1093/infdis/jir610

Abed, Y., Pizzorno, A., and Boivin, G. (2012). Therapeutic activity of intramuscular peramivir in mice infected with a recombinant influenza A/WSN/33 (H1N1) virus containing the $\mathrm{H} 275 \mathrm{Y}$ neuraminidase mutation. Antimicrob. Agents Chemother. 56, 4375-4380. doi: 10.1128/AAC.00753-12

Abed, Y., Simon, P., and Boivin, G. (2010). Prophylactic activity of intramuscular peramivir in mice infected with a recombinant influenza A/WSN/33 (H1N1) virus containing the H274Y neuraminidase mutation. Antimicrob. Agents Chemother. 54, 2819-2822. doi: 10.1128/AAC.01681-09

Alexander, P. E., De, P., and Rave, S. (2009). Is H9N2 avian influenza virus a pandemic potential? Can. J. Infect. Dis. Med. Microbiol. 20, e35-e36.

Atiee, G., Lasseter, K., Baughman, S., McCullough, A., Collis, P., Hollister, A., et al. (2012). Absence of pharmacokinetic interaction between intravenous peramivir and oral oseltamivir or rimantadine in humans. J. Clin. Pharmacol. 52, 1410-1419. doi: 10.1177/0091270011414574

Azuma, T., Ishiuchi, H., Inoyama, T., Teranishi, Y., Yamaoka, M., Sato, T., et al. (2015). Detection of peramivir and laninamivir, new anti-influenza drugs, in sewage effluent and river waters in Japan. PLoS ONE 10:e0131412. doi: 10.1371/journal.pone.0131412

Babu, Y. S., Chand, P., Bantia, S., Kotian, P., Dehghani, A., El-Kattan, Y., et al. (2000). BCX-1812 (RWJ-270201):? discovery of a novel, highly potent, orally active, and selective influenza neuraminidase inhibitor through structure-based drug design. J. Med. Chem. 43, 3482-3486. doi: 10.1021/jm0002679

Baek, Y. H., Song, M.-S., Lee, E.-Y., Kim, Y., Kim, E.-H., Park, S.-J., et al. (2015). Profiling and characterization of influenza virus N1 strains potentially resistant to multiple neuraminidase inhibitors. J. Virol. 89, 287-299. doi: 10.1128/JVI.02485-14

Balgi, A. D., Wang, J., Cheng, D. Y. H., Ma, C., Pfeifer, T. A., Shimizu, Y., et al. (2013). Inhibitors of the influenza A virus M2 proton channel discovered using a high-throughput yeast growth restoration assay. PLOS ONE 8:e55271. doi: 10.1371/journal.pone.0055271

Banerjee, I., Yamauchi, Y., Helenius, A., and Horvath, P. (2013). High-content analysis of sequential events during the early phase of influenza A virus infection. PLoS ONE 8:e68450. doi: 10.1371/journal.pone.0068450

Bantia, S., Arnold, C. S., Parker, C. D., Upshaw, R., and Chand, P. (2006). Antiinfluenza virus activity of peramivir in mice with single intramuscular injection. Antiviral Res. 69, 39-45. doi: 10.1016/j.antiviral.2005.10.002

Bantia, S., Kellogg, D., Parker, C., Upshaw, R., Ilyushina, N. A., and Babu, Y. S. (2011). A single intramuscular injection of neuraminidase inhibitor peramivir demonstrates antiviral activity against novel pandemic A/California/04/2009 (H1N1) influenza virus infection in mice. Antiviral Res. 90, 17-21. doi: 10.1016/j.antiviral.2011.02.001

Bantia, S., Kellogg, D., Parker, C. D., and Babu, Y. S. (2010). Combination of peramivir and rimantadine demonstrate synergistic antiviral effects in sublethal influenza A (H3N2) virus mouse model. Antiviral Res. 88, 276-280. doi: 10.1016/j.antiviral.2010.09.020

Bantia, S., Parker, C. D., Ananth, S. L., Horn, L. L., Andries, K., Chand, P., et al. (2001). Comparison of the anti-influenza virus activity of RWJ-270201 with those of oseltamivir and zanamivir. Antimicrob. Agents Chemother. 45, 1162-1167. doi: 10.1128/AAC.45.4.1162-1167.2001

Baranovich, T., Wong, S.-S., Armstrong, J., Marjuki, H., Webby, R. J., Webster, R. G., et al. (2013). T-705 (Favipiravir) induces lethal mutagenesis in influenza A H1N1 viruses in vitro. J. Virol. 87, 3741-3751. doi: 10.1128/JVI.02346-12

Barroso, L., Treanor, J., Gubareva, L., and Hayden, F. G. (2005). Efficacy and tolerability of the oral neuraminidase inhibitor peramivir in experimental human influenza: randomized, controlled trials for prophylaxis and treatment. Antivir. Ther. 10, 901-910.

Basu, A., Antanasijevic, A., Wang, M., Li, B., Mills, D. M., Ames, J. A., et al. (2014). New small molecule entry inhibitors targeting hemagglutinin-mediated influenza A virus fusion. J. Virol. 88, 1447-1460. doi: 10.1128/JVI.01225-13
BioCryst Pharmaceuticals (2015). A Phase II, Multicenter, Randomized, Placebo -Controlled, Study To Evaluate The Efficacy and Safety of Intramuscular Peramivir $600 \mathrm{mg}$ in Subjects With Uncomplicated Acute Influenza - Full Text View - ClinicalTrials.gov. Available at: https://clinicaltrials.gov/ct2/show/NCT 00705406? term $=$ peramivir\&rank $=10$ [accessed December16, 2015].

Boltz, D. A., Ilyushina, N. A., Arnold, C. S., Babu, Y. S., Webster, R. G., and Govorkova, E. A. (2008). Intramuscularly administered neuraminidase inhibitor peramivir is effective against lethal $\mathrm{H} 5 \mathrm{~N} 1$ influenza virus in mice. Antiviral Res. 80, 150-157. doi: 10.1016/j.antiviral.2008.05.012

Burmeister, W. P., Ruigrok, R. W., and Cusack, S. (1992). The 2.2 A resolution crystal structure of influenza B neuraminidase and its complex with sialic acid. EMBO J. 11, 49-56.

Burnham, A. J., Baranovich, T., and Govorkova, E. A. (2013). Neuraminidase inhibitors for influenza B virus infection: efficacy and resistance. Antiviral Res. 100, 520-534. doi: 10.1016/j.antiviral.2013.08.023

Chairat, K., Tarning, J., White, N. J., and Lindegardh, N. (2013). Pharmacokinetic properties of anti-influenza neuraminidase inhibitors. J. Clin. Pharmacol. 53, 119-139. doi: $10.1177 / 0091270012440280$

Chen, H.-W., Cheng, J. X., Liu, M.-T., King, K., Peng, J.-Y., Zhang, X.-Q., et al. (2013). Inhibitory and combinatorial effect of diphyllin, a v-ATPase blocker, on influenza viruses. Antiviral Res. 99, 371-382. doi: 10.1016/j.antiviral.2013.06.014

Chen, X., Si, L., Liu, D., Proksch, P., Zhang, L., Zhou, D., et al. (2015). Neoechinulin B and its analogues as potential entry inhibitors of influenza viruses, targeting viral hemagglutinin. Eur. J. Med. Chem. 93, 182-195. doi: 10.1016/j.ejmech.2015.02.006

Clay, P. G., Adiga, R., Taylor, T. A. H., Alsup, R., Gerk, P. M., and McRae, M. (2011). Postpartum pharmacokinetics of peramivir in the treatment of 2009 H1N1 influenza: a case report. Obstet. Gynecol. 118, 463-467. doi: 10.1097/AOG.0b013e31821b1b3e

Colman, P. M. (1994). Influenza virus neuraminidase: structure, antibodies, and inhibitors. Protein Sci. 3, 1687-1696. doi: 10.1002/pro.5560031007

Colman, P. M., Hoyne, P. A., and Lawrence, M. C. (1993). Sequence and structure alignment of paramyxovirus hemagglutinin-neuraminidase with influenza virus neuraminidase. J. Virol. 67, 2972-2980.

Colman, P. M., Varghese, J. N., and Laver, W. G. (1983). Structure of the catalytic and antigenic sites in influenza virus neuraminidase. Nature 303, 41-44. doi: $10.1038 / 303041 \mathrm{a} 0$

Cox, N. J., and Subbarao, K. (2000). Global epidemiology of influenza: past and present. Annu. Rev. Med. 51, 407-421. doi: 10.1146/annurev.med. 51.1.407

Dapat, C., Suzuki, Y., Saito, R., Kyaw, Y., Myint, Y. Y., Lin, N., et al. (2010). Rare influenza A (H3N2) variants with reduced sensitivity to antiviral drugs. Emerg. Infect. Dis. 16, 493-496. doi: 10.3201/eid1603.091321

de Jong, M. D., Ison, M. G., Monto, A. S., Metev, H., Clark, C., O’Neil, B., et al. (2014). Evaluation of intravenous peramivir for treatment of influenza in hospitalized patients. Clin. Infect. Dis. Off. Publ. Infect. Dis. Soc. Am. 59, e172-e185. doi: 10.1093/cid/ciu632

de Vries, E., Tscherne, D. M., Wienholts, M. J., Cobos-Jiménez, V., Scholte, F., García-Sastre, A., et al. (2011). Dissection of the influenza A virus endocytic routes reveals macropinocytosis as an alternative entry pathway. PLoS Pathog. 7:e1001329. doi: 10.1371/journal.ppat.1001329

Drusano, G. L., Preston, S. L., Smee, D., Bush, K., Bailey, K., and Sidwell, R. W. (2001). Pharmacodynamic evaluation of RWJ-270201, a novel neuraminidase inhibitor, in a lethal murine model of influenza predicts efficacy for once-daily dosing. Antimicrob. Agents Chemother. 45, 2115-2118. doi: 10.1128/AAC.45.7.2115-2118.2001

DuBois, R. M., Slavish, P. J., Baughman, B. M., Yun, M.-K., Bao, J., Webby, R. J., et al. (2012). Structural and biochemical basis for development of influenza virus inhibitors targeting the PA endonuclease. PLoS Pathog. 8:e1002830. doi: 10.1371/journal.ppat.1002830

Edinger, T. O., Pohl, M. O., and Stertz, S. (2014). Entry of influenza A virus: host factors and antiviral targets. J. Gen. Virol. 95, 263-277. doi: 10.1099/vir.0.059477-0

Farooqui, A., Huang, L., Wu, S., Cai, Y., Su, M., Lin, P., et al. (2015). Assessment of antiviral properties of Peramivir against H7N9 avian influenza virus in an experimental mouse model. Antimicrob. Agents Chemother. 59, 7255-7264. doi: 10.1128/AAC.01885-15. 
Food and Drug Administration (2015a). Press Announcements: FDA Authorizes Emergency Use of Intravenous Antiviral Peramivir for 2009 H1N1 Influenza for Certain Patients, Settings. Available at: http://www.fda.gov/NewsEvents/Newsr oom/PressAnnouncements/ucm187813.htm [accessed December 22, 2015a].

Food and Drug Administration (2015b). RAPIVABTM (Peramivir Injection), for Intravenous use Initial U.S. Approval 2014: Highlights of Prescribing Information. Available at: http://www.accessdata.fda.gov/drugsatfda docs/label/2014/206426lbl.pdf [accessed December 25, 2015b].

Furuta, Y., Gowen, B. B., Takahashi, K., Shiraki, K., Smee, D. F., and Barnard, D. L. (2013). Favipiravir (T-705), a novel viral RNA polymerase inhibitor. Antiviral Res. 100, 446-454. doi: 10.1016/j.antiviral.2013.09.015

Furuta, Y., Takahashi, K., Kuno-Maekawa, M., Sangawa, H., Uehara, S., Kozaki, K., et al. (2005). Mechanism of action of T-705 against influenza virus. Antimicrob. Agents Chemother. 49, 981-986. doi: 10.1128/AAC.49.3.981-986.2005

Govorkova, E. A., Leneva, I. A., Goloubeva, O. G., Bush, K., and Webster, R. G. (2001). Comparison of efficacies of RWJ-270201, zanamivir, and oseltamivir against H5N1, H9N2, and Other avian influenza viruses. Antimicrob. Agents Chemother. 45, 2723-2732. doi: 10.1128/AAC.45.10.2723-2732.2001

Govorkova, E. A., and Webster, R. G. (2010). Combination chemotherapy for influenza. Viruses 2, 1510-1529. doi: 10.3390/v2081510

Gubareva, L. V., Webster, R. G., and Hayden, F. G. (2001). Comparison of the activities of zanamivir, oseltamivir, and RWJ-270201 against clinical isolates of influenza virus and neuraminidase inhibitor-resistant variants. Antimicrob. Agents Chemother. 45, 3403-3408. doi: 10.1128/AAC.45.12.3403-3408.2001

Haffizulla, J., Hartman, A., Hoppers, M., Resnick, H., Samudrala, S., Ginocchio, C., et al. (2014). Effect of nitazoxanide in adults and adolescents with acute uncomplicated influenza: a double-blind, randomised, placebo-controlled, phase 2b/3 trial. Lancet Infect. Dis. 14, 609-618. doi: 10.1016/S14733099(14)70717-0

Hamilton, B. S., Whittaker, G. R., and Daniel, S. (2012). Influenza virus-mediated membrane fusion: determinants of hemagglutinin fusogenic activity and experimental approaches for assessing virus fusion. Viruses 4, 1144-1168. doi: $10.3390 / \mathrm{v} 4071144$

Harada-Shirado, K., Ikeda, K., Furukawa, M., Sukegawa, M., Takahashi, H., Shichishima-Nakamura, A., et al. (2014). Severe immune thrombocytopenia possibly elicited by the anti-influenza viral agent peramivir. Intern. Med. 53, 2369-2371. doi: 10.2169/internalmedicine.53.2330

Hartshorn, K. L., Webby, R., White, M. R., Tecle, T., Pan, C., Boucher, S., et al. (2008). Role of viral hemagglutinin glycosylation in anti-influenza activities of recombinant surfactant protein D. Respir. Res. 9:65. doi: 10.1186/14659921-9-65

Hastings, J. C., Selnick, H., Wolanski, B., and Tomassini, J. E. (1996). Antiinfluenza virus activities of 4-substituted 2,4-dioxobutanoic acid inhibitors. Antimicrob. Agents Chemother. 40, 1304-1307.

Hata, M., Tsuzuki, M., Goto, Y., Kumagai, N., Harada, M., Hashimoto, M., et al. (2007). High frequency of amantadine-resistant influenza A (H3N2) viruses in the 2005-2006 season and rapid detection of amantadine-resistant influenza A (H3N2) viruses by MAMA-PCR. Jpn. J. Infect. Dis. 60, 202-204.

Hay, A. J., Zambon, M. C., Wolstenholme, A. J., Skehel, J. J., and Smith, M. H. (1986). Molecular basis of resistance of influenza A viruses to amantadine. J. Antimicrob. Chemother. 18, 19-29. doi: 10.1093/jac/18.Supplement_B.19

Hayashi, K., Iwasa, K., Morinaga, A., Ono, K., and Yamada, M. (2015). Exacerbation of myasthenia gravis by intravenous peramivir. Muscle Nerve 51, 935-936. doi: $10.1002 /$ mus. 24594

Hayden, F. (2009). Developing new antiviral agents for influenza treatment: what does the future hold? Clin. Infect. Dis. 48, S3-S13. doi: 10.1086/591851

Hayden, F. G., Treanor, J. J., Fritz, R. S., Lobo, M., Betts, R. F., Miller, M., et al. (1999). Use of the oral neuraminidase inhibitor oseltamivir in experimental human influenza: randomized controlled trials for prevention and treatment. JAMA 282, 1240-1246. doi: 10.1001/jama.282.13.1240

Hernandez, J. E., Adiga, R., Armstrong, R., Bazan, J., Bonilla, H., Bradley, J., et al. (2011). Clinical experience in adults and children treated with intravenous peramivir for 2009 influenza A (H1N1) under an emergency IND program in the united states. Clin. Infect. Dis. 52, 695-706. doi: 10.1093/cid/cir001

Higgins, R. R., Beniprashad, M., Chong-King, E., Li, Y., Bastien, N., Low, D. E., et al. (2012). Recovery of influenza B virus with the H273Y point mutation in the neuraminidase active site from a human patient. J. Clin. Microbiol. 50, 2500-2502. doi: 10.1128/JCM.00682-12
Hikita, T., Hikita, H., Hikita, F., Hikita, N., and Hikita, S. (2012). Clinical effectiveness of peramivir in comparison with other neuraminidase inhibitors in pediatric influenza patients. Int. J. Pediatr. 2012:e834181. doi: $10.1155 / 2012 / 834181$

Ikematsu, H., Kawai, N., Iwaki, N., and Kashiwagi, S. (2014). In vitro neuraminidase inhibitory activity of four neuraminidase inhibitors against influenza virus isolates in the 2011-2012 season in Japan. J. Infect. Chemother. Off. J. Jpn. Soc. Chemother. 20, 77-80. doi: 10.1016/j.jiac.2013.07.002

Ikematsu, H., Kawai, N., Iwaki, N., and Kashiwagi, S. (2015a). In vitro neuraminidase inhibitory activity of four neuraminidase inhibitors against clinical isolates of influenza virus in the Japanese 2012-2013 season. J. Infect. Chemother. Off. J. Jpn. Soc. Chemother. 21, 39-42. doi: 10.1016/j.jiac.2014.08.030

Ikematsu, H., Kawai, N., Iwaki, N., and Kashiwagi, S. (2015b). In vitro neuraminidase inhibitory activity of four neuraminidase inhibitors against clinical isolates of the influenza virus circulating in the Japanese 2013-2014 season. J. Infect. Chemother. 21, 634-638. doi: 10.1016/j.jiac.2015.05.004

Ison, M. G. (2011). Antivirals and resistance: influenza virus. Curr. Opin. Virol. 1, 563-573. doi: 10.1016/j.coviro.2011.09.002

Ison, M. G., Fraiz, J., Heller, B., Jauregui, L., Mills, G., O’Riordan, W., et al. (2014). Intravenous peramivir for treatment of influenza in hospitalized patients. Antivir. Ther. 19, 349-361. doi: 10.3851/IMP2680

Ison, M. G., Hui, D. S., Clezy, K., O’Neil, B. J., Flynt, A., Collis, P. J., et al. (2013). A clinical trial of intravenous peramivir compared with oral oseltamivir for the treatment of seasonal influenza in hospitalized adults. Antivir. Ther. 18, 651-661. doi: 10.3851/IMP2442

Itoh, Y., Shichinohe, S., Nakayama, M., Igarashi, M., Ishii, A., Ishigaki, H., et al. (2015). Emergence of H7N9 influenza A virus resistant to neuraminidase inhibitors in nonhuman primates. Antimicrob. Agents Chemother. 59, 49624973. doi: 10.1128/AAC.00793-15

Iyer, G. R., Liao, S., and Massarella, J. (2002). Population analysis of the pharmacokinetics and pharmacodynamics of RWJ-270201 (BCX-1812) in treating experimental influenza $\mathrm{A}$ and $\mathrm{B}$ virus in healthy volunteers. AAPS PharmSci. 4, 29-38. doi: 10.1208/ps040422

Jefferson, T. O., Demicheli, V., Deeks, J. J., and Rivetti, D. (2001). Amantadine and rimantadine for preventing and treating influenza $\mathrm{A}$ in adults. Cochrane Database Syst. Rev. CD001169. doi: 10.1002/14651858.CD001169

Jones, J. C., Turpin, E. A., Bultmann, H., Brandt, C. R., and SchultzCherry, S. (2006). Inhibition of influenza virus infection by a novel antiviral peptide that targets viral attachment to cells. J. Virol. 80, 11960-11967. doi: 10.1128/JVI.01678-06

Kakuta, M., Kubo, S., Tanaka, M., Tobiume, S., Tomozawa, T., and Yamashita, M. (2013). Efficacy of a single intravenous administration of laninamivir (an active metabolite of laninamivir octanoate) in an influenza virus infection mouse model. Antiviral Res. 100, 190-195. doi: 10.1016/j.antiviral.2013. 08.004

Kim, C. U., Lew, W., Williams, M. A., Liu, H., Zhang, L., Swaminathan, S., et al. (1997). Influenza neuraminidase inhibitors possessing a novel hydrophobic interaction in the enzyme active site:? design, synthesis, and structural analysis of carbocyclic sialic acid analogues with potent anti-influenza activity. J. Am. Chem. Soc. 119, 681-690. doi: 10.1021/ja963036t

Kitano, M., Itoh, Y., Ishigaki, H., Nakayama, M., Ishida, H., Pham, V. L., et al. (2014). Efficacy of repeated intravenous administration of peramivir against highly pathogenic avian influenza A ( $\mathrm{H} 5 \mathrm{~N} 1)$ virus in cynomolgus macaques. Antimicrob. Agents Chemother. 58, 4795-4803. doi: 10.1128/AAC. 02817-14

Kitano, M., Itoh, Y., Kodama, M., Ishigaki, H., Nakayama, M., Ishida, H., et al. (2011). Efficacy of single intravenous injection of peramivir against influenza $\mathrm{B}$ virus infection in ferrets and cynomolgus macaques. Antimicrob. Agents Chemother. 55, 4961-4970. doi: 10.1128/AAC.00412-11

Kitano, M., Kodama, M., Itoh, Y., Kanazu, T., Kobayashi, M., Yoshida, R., et al. (2013). Efficacy of repeated intravenous injection of peramivir against influenza A (H1N1) 2009 virus infection in immunosuppressed mice. Antimicrob. Agents Chemother. 57, 2286-2294. doi: 10.1128/AAC.02324-12

Kohno, S., Kida, H., Mizuguchi, M., Hirotsu, N., Ishida, T., Kadota, J., et al. (2011a). Intravenous peramivir for treatment of influenza A and B virus infection in high-risk patients?. Antimicrob. Agents Chemother. 55, 2803-2812. doi: 10.1128/AAC.01718-10 
Kohno, S., Kida, H., Mizuguchi, M., and Shimada, J. (2010). Efficacy and safety of intravenous peramivir for treatment of seasonal influenza virus infection. Antimicrob. Agents Chemother. 54, 4568-4574. doi: 10.1128/AAC.00474-10

Kohno, S., Yen, M.-Y., Cheong, H.-J., Hirotsu, N., Ishida, T., Kadota, J., et al. (2011b). Phase III randomized, double-blind study comparing singledose intravenous peramivir with oral oseltamivir in patients with seasonal influenza virus infection. Antimicrob. Agents Chemother. 55, 5267-5276. doi: 10.1128/AAC.00360-11

Komeda, T., Ishii, S., Itoh, Y., Ariyasu, Y., Sanekata, M., Yoshikawa, T., et al. (2014). Post-marketing safety and effectiveness evaluation of the intravenous anti-influenza neuraminidase inhibitor peramivir (I): a drug use investigation. J. Infect. Chemother. 20, 689-695. doi: 10.1016/j.jiac.2014.07.006

Komeda, T., Ishii, S., Itoh, Y., Ariyasu, Y., Sanekata, M., Yoshikawa, T., et al. (2015). Post-marketing safety and effectiveness evaluation of the intravenous anti-influenza neuraminidase inhibitor peramivir (II): a pediatric drug use investigation. J. Infect. Chemother. 21, 194-201. doi: 10.1016/j.jiac.2014.11.009

Krammer, F., and Palese, P. (2015). Advances in the development of influenza virus vaccines. Nat. Rev. Drug Discov. 14, 167-182. doi: 10.1038/nrd4529

Lam, T. T.-Y., Zhou, B., Wang, J., Chai, Y., Shen, Y., Chen, X., et al. (2015). Dissemination, divergence and establishment of H7N9 influenza viruses in China. Nature 522, 102-105. doi: 10.1038/nature14348

Leang, S.-K., Kwok, S., Sullivan, S. G., Maurer-Stroh, S., Kelso, A., Barr, I. G., et al. (2014). Peramivir and laninamivir susceptibility of circulating influenza A and B viruses. Influenza Other Respir. Viruses 8, 135-139. doi: 10.1111/irv.12187

Leser, G. P., and Lamb, R. A. (2005). Influenza virus assembly and budding in raftderived microdomains: a quantitative analysis of the surface distribution of HA, NA and M2 proteins. Virology 342, 215-227. doi: 10.1016/j.virol.2005.09.049

Leu, C.-H., Yang, M.-L., Chung, N.-H., Huang, Y.-J., Su, Y.-C., Chen, Y.-C., et al. (2015). Kallistatin ameliorates influenza virus pathogenesis by inhibition of kallikrein-related peptidase 1-mediated cleavage of viral hemagglutinin. Antimicrob. Agents Chemother. 59, 5619-5630. doi: 10.1128/AAC.00065-15

Li, F., Ma, C., and Wang, J. (2015). Inhibitors targeting the influenza virus hemagglutinin. Curr. Med. Chem. 22, 1361-1382. doi: $10.2174 / 0929867322666150227153919$

Liu, C., Eichelberger, M. C., Compans, R. W., and Air, G. M. (1995). Influenza type A virus neuraminidase does not play a role in viral entry, replication, assembly, or budding. J. Virol. 69, 1099-1106.

Malaisree, M., Rungrotmongkol, T., Decha, P., Intharathep, P., Aruksakunwong, O., and Hannongbua, S. (2008). Understanding of known drug-target interactions in the catalytic pocket of neuraminidase subtype N1. Proteins 71, 1908-1918. doi: 10.1002/prot.21897

Malakhov, M. P., Aschenbrenner, L. M., Smee, D. F., Wandersee, M. K., Sidwell, R. W., Gubareva, L. V., et al. (2006). Sialidase fusion protein as a novel broadspectrum inhibitor of influenza virus infection. Antimicrob. Agents Chemother. 50, 1470-1479. doi: 10.1128/AAC.50.4.1470-1479.2006

Mammen, M., Dahmann, G., and Whitesides, G. M. (1995). Effective inhibitors of hemagglutination by influenza virus synthesized from polymers having active ester groups. Insight into mechanism of inhibition. J. Med. Chem. 38, 4179-4190. doi: 10.1021/jm00021a007

Mancuso, C. E., Gabay, M. P., Steinke, L. M., and Vanosdol, S. J. (2010). Peramivir: an intravenous neuraminidase inhibitor for the treatment of 2009 H1N1 influenza. Ann. Pharmacother. 44, 1240-1249. doi: 10.1345/aph.1P031

Marjuki, H., Mishin, V. P., Chesnokov, A. P., Jones, J., Cruz, J. A. D. L., Sleeman, K., et al. (2015). Characterization of drug-resistant influenza A (H7N9) variants isolated from an oseltamivir-treated patient in Taiwan. J. Infect. Dis. 211, 249-257. doi: 10.1093/infdis/jiu447

Matsubara, T., Onishi, A., Saito, T., Shimada, A., Inoue, H., Taki, T., et al. (2010). Sialic acid-mimic peptides as hemagglutinin inhibitors for anti-influenza therapy. J. Med. Chem. 53, 4441-4449. doi: 10.1021/jm1002183

Matsuo, Y., Ishibashi, T., Hollister, A. S., and Wajima, T. (2015). Population pharmacokinetics of peramivir in healthy volunteers and influenza patients. Antimicrob. Agents Chemother. 59, 6755-6762. doi: 10.1128/AAC.00799-15

McGeoch, D., Fellner, P., and Newton, C. (1976). Influenza virus genome consists of eight distinct RNA species. Proc. Natl. Acad. Sci. U.S.A. 73, 3045-3049. doi: 10.1073/pnas.73.9.3045

McLaughlin, M. M., Skoglund, E. W., and Ison, M. G. (2015). Peramivir: an intravenous neuraminidase inhibitor. Expert Opin. Pharmacother. 16, 18891900. doi: $10.1517 / 14656566.2015 .1066336$
Meijer, A., Rebelo-de-Andrade, H., Correia, V., Besselaar, T., Drager-Dayal, R., Fry, A., et al. (2014). Global update on the susceptibility of human influenza viruses to neuraminidase inhibitors, 2012-2013. Antiviral Res. 110, 31-41. doi: 10.1016/j.antiviral.2014.07.001

Memoli, M. J., Hrabal, R. J., Hassantoufighi, A., Eichelberger, M. C., and Taubenberger, J. K. (2010). Rapid selection of oseltamivirand peramivirresistant pandemic H1N1 virus during therapy in 2 immunocompromised hosts. Clin. Infect. Dis. 50, 1252-1255. doi: 10.1086/651605

Miller, P. E., Rambachan, A., Hubbard, R. J., Li, J., Meyer, A. E., Stephens, P., et al. (2013). Supply of neuraminidase inhibitors related to reduced influenza A (H1N1) mortality during the 2009-2010 H1N1 pandemic: summary of an ecological study. Influenza Other Respir. Viruses 7(Suppl. 2), 82-86. doi: 10.1111/irv.12092

Nicholson, K., Aoki, F., Osterhaus, A., Trottier, S., Carewicz, O., Mercier, C., et al. (2000). Efficacy and safety of oseltamivir in treatment of acute influenza: a randomised controlled trial. Lancet 355, 1845-1850. doi: 10.1016/S01406736(00)02288-1

Nicholson, K. G., Wood, J. M., and Zambon, M. (2003). Influenza. Lancet 362, 1733-1745. doi: 10.1016/S0140-6736(03)14854-4

Onishi, M., Kitano, M., Taniguchi, K., Homma, T., Kobayashi, M., Yoshinaga, T., et al. (2015). Intravenous peramivir inhibits viral replication, and leads to bacterial clearance and prevention of mortality during murine bacterial co-infection caused by influenza A (H1N1)pdm09 virus and Streptococcus pneumoniae. Antiviral Res. 117, 52-59. doi: 10.1016/j.antiviral.2015.02.012

Osterholm, M. T., Kelley, N. S., Sommer, A., and Belongia, E. A. (2012). Efficacy and effectiveness of influenza vaccines: a systematic review and meta-analysis. Lancet Infect. Dis. 12, 36-44. doi: 10.1016/S1473-3099(11)70295-X

Palese, P. (1977). The genes of influenza virus. Cell 10, 1-10. doi: 10.1016/00928674(77)90133-7

Palese, P., and Compans, R. W. (1976). Inhibition of influenza virus replication in tissue culture by 2-deoxy-2,3-dehydro- $\mathrm{N}$-trifluoroacetylneuraminic acid (FANA): mechanism of action. J. Gen. Virol. 33, 159-163. doi: 10.1099/00221317-33-1-159

Palese, P., and Schulman, J. L. (1976). Mapping of the influenza virus genome: identification of the hemagglutinin and the neuraminidase genes. Proc. Natl. Acad. Sci. U.S.A. 73, 2142-2146. doi: 10.1073/pnas.73.6.2142

Park, S., Kim, J. I., Lee, I., Lee, S., Hwang, M.-W., Bae, J.-Y., et al. (2014). Combination effects of peramivir and favipiravir against oseltamivir-resistant 2009 pandemic influenza A (H1N1) infection in mice. PLoS ONE 9:e101325. doi: 10.1371/journal.pone.0101325

Quinn, S. C., Hilyard, K., Castaneda-Angarita, N., and Freimuth, V. S. (2015). Public acceptance of peramivir during the 2009 H1N1 influenza pandemic: implications for other drugs or vaccines under emergency use authorizations. Disaster Med. Public Health Prep. 9, 166-174. doi: 10.1017/dmp. 2014.156

Renaud, C., Pergam, S. A., Polyak, C., Jain, R., Kuypers, J., Englund, J. A., et al. (2010). Early emergence of an H275Y mutation in a hematopoietic cell transplant recipient treated with intravenous peramivir. Transpl. Infect. Dis. 12, 513-517. doi: 10.1111/j.1399-3062.2010.00582.x

Rossignol, J.-F. (2014). Nitazoxanide: a first-in-class broad-spectrum antiviral agent. Antiviral Res. 110, 94-103. doi: 10.1016/j.antiviral.2014.07.014

Rossignol, J. F., Frazia, S. L., Chiappa, L., Ciucci, A., and Santoro, M. G. (2009). Thiazolides, a new class of anti-influenza molecules targeting viral hemagglutinin at the post-translational level. J. Biol. Chem. 284, 29798-29808. doi: 10.1074/jbc.M109.029470

Salomon, R., and Webster, R. G. (2009). The influenza virus enigma. Cell 136, 402-410. doi: 10.1016/j.cell.2009.01.029

Sauter, N. K., Hanson, J. E., Glick, G. D., Brown, J. H., Crowther, R. L., Park, S. J., et al. (1992). Binding of influenza virus hemagglutinin to analogs of its cell-surface receptor, sialic acid: analysis by proton nuclear magnetic resonance spectroscopy and X-ray crystallography. Biochemistry (Mosc.) 31, 9609-9621. doi: 10.1021/bi00155a013

Scheetz, M. H., Griffith, M. M., Ghossein, C., Hollister, A. S., and Ison, M. G. (2011). Pharmacokinetic assessment of peramivir in a hospitalized adult undergoing continuous venovenous hemofiltration. Ann. Pharmacother. 45:e64. doi: 10.1345/aph.1Q437

Semenova, N. P., Prokudina, E. N., Livov, D. K., and Nebol'sin, V. E. (2010). [Effect of the antiviral drug Ingaviruin on intracellular transformations and import 
into the nucleus of influenza A virus nucleocapsid protein]. Vopr. Virusol. 55, $17-20$.

Shetty, A. K., and Peek, L. A. (2012). Peramivir for the treatment of influenza. Expert Rev. Anti Infect. Ther. 10, 123-143. doi: 10.1586/eri.11.174

Sidwell, R. W., Smee, D. F., Huffman, J. H., Barnard, D. L., Bailey, K. W., Morrey, J. D., et al. (2001a). In vivo influenza virus-inhibitory effects of the cyclopentane neuraminidase inhibitor RWJ-270201. Antimicrob. Agents Chemother. 45, 749757. doi: 10.1128/AAC.45.3.749-757.2001

Sidwell, R. W., Smee, D. F., Huffman, J. H., Barnard, D. L., Morrey, J. D., Bailey, K. W., et al. (2001b). Influence of virus strain, challenge dose, and time of therapy initiation on the in vivo influenza inhibitory effects of RWJ-270201. Antiviral Res. 51, 179-187. doi: 10.1016/S0166-3542(01)00149-8

Smee, D. F., Hurst, B. L., Wong, M.-H., Tarbet, E. B., Babu, Y. S., Klumpp, K., et al. (2010). Combinations of oseltamivir and peramivir for the treatment of influenza A (H1N1) virus infections in cell culture and in mice. Antiviral Res. 88, 38-44. doi: 10.1016/j.antiviral.2010.07.003

Smee, D. F., Sidwell, R. W., Morrison, A. C., Bailey, K. W., Baum, E. Z., Ly, L., et al. (2001). Characterization of an influenza A (H3N2) virus resistant to the cyclopentane neuraminidase inhibitor RWJ-270201. Antiviral Res. 52, 251-259. doi: 10.1016/S0166-3542(01)00168-1

Sorbello, A., Jones, S. C., Carter, W., Struble, K., Boucher, R., Truffa, M., et al. (2012). Emergency use authorization for intravenous peramivir: evaluation of safety in the treatment of hospitalized patients infected with $2009 \mathrm{H} 1 \mathrm{~N} 1$ influenza A virus. Clin. Infect. Dis. 55, 1-7. doi: 10.1093/cid/cis351

Stoll, V., Stewart, K. D., Maring, C. J., Muchmore, S., Giranda, V., Gu, Y. Y., et al. (2003). Influenza neuraminidase inhibitors:? structure-based design of a novel inhibitor series. Biochemistry (Mosc.) 42, 718-727. doi: 10.1021/bi0205449

Sugaya, N., Kohno, S., Ishibashi, T., Wajima, T., and Takahashi, T. (2012). Efficacy, safety, and pharmacokinetics of intravenous peramivir in children with 2009 pandemic H1N1 influenza A virus infection. Antimicrob. Agents Chemother. 56, 369-377. doi: 10.1128/AAC.00132-11

Sweet, C., Jakeman, K. J., Bush, K., Wagaman, P. C., McKown, L. A., Streeter, A. J., et al. (2002). Oral administration of cyclopentane neuraminidase inhibitors protects ferrets against influenza virus infection. Antimicrob. Agents Chemother. 46, 996-1004. doi: 10.1128/AAC.46.4.996-1004.2002

Takashita, E., Ejima, M., Itoh, R., Miura, M., Ohnishi, A., Nishimura, H., et al. (2014). A community cluster of influenza A (H1N1)pdm09 virus exhibiting cross-resistance to oseltamivir and peramivir in Japan, november to december 2013. Euro. Surveill 19:20666. doi: 10.2807/1560-7917.ES2014.19. 1.20666

Tamerius, J., Nelson, M. I., Zhou, S. Z., Viboud, C., Miller, M. A., and Alonso, W. J. (2010). Global influenza seasonality: reconciling patterns across temperate and tropical regions. Environ. Health Perspect. 119, 439-445. doi: 10.1289/ehp.1002383

Tan, K.-X., Jacob, S. A., Chan, K.-G., and Lee, L.-H. (2015). An overview of the characteristics of the novel avian influenza A H7N9 virus in humans. Front. Microbiol. 6:140. doi: 10.3389/fmicb.2015.00140

Tanaka, A., Nakamura, S., Seki, M., Iwanaga, N., Kajihara, T., Kitano, M., et al. (2015). The effect of intravenous peramivir, compared with oral oseltamivir, on the outcome of post-influenza pneumococcal pneumonia in mice. Antivir. Ther. 20, 11-19. doi: 10.3851/IMP2744

Tompkins, S. M., Lo, C.-Y., Tumpey, T. M., and Epstein, S. L. (2004). Protection against lethal influenza virus challenge by RNA interference in vivo. Proc. Natl. Acad. Sci. U.S.A. 101, 8682-8686. doi: 10.1073/pnas.0402630101

Tong, S., Li, Y., Rivailler, P., Conrardy, C., Castillo, D. A. A., Chen, L.-M., et al. (2012). A distinct lineage of influenza A virus from bats. Proc. Natl. Acad. Sci. U.S.A. 109, 4269-4274. doi: 10.1073/pnas.1116200109

Tong, S., Zhu, X., Li, Y., Shi, M., Zhang, J., Bourgeois, M., et al. (2013). New world bats harbor diverse influenza A viruses. PLoS Pathog. 9:e1003657. doi: 10.1371/journal.ppat.1003657

Treanor, J. J., Hayden, F. G., Vrooman, P. S., Barbarash, R., Bettis, R., and Riff, D. (2000). Efficacy and safety of the oral neuraminidase inhibitor oseltamivir in treating acute influenza: a randomized controlled trial. JAMA 283, 1016-1024. doi: 10.1001/jama.283.8.1016

von Itzstein, M. (2007). The war against influenza: discovery and development of sialidase inhibitors. Nat. Rev. Drug Discov. 6, 967-974. doi: 10.1038/nrd2400

von Itzstein, M., Wu, W.-Y., Kok, G. B., Pegg, M. S., Dyason, J. C., Jin, B., et al. (1993). Rational design of potent sialidase-based inhibitors of influenza virus replication. Nature 363, 418-423. doi: 10.1038/363418a0
Webster, R. G., Bean, W. J., Gorman, O. T., Chambers, T. M., and Kawaoka, Y. (1992). Evolution and ecology of influenza A viruses. Microbiol. Rev. 56, $152-179$.

White, K. M., De Jesus, P., Chen, Z., Abreu, P., Barile, E., Mak, P. A., et al (2015). A potent anti-influenza compound blocks fusion through stabilization of the prefusion conformation of the hemagglutinin protein. ACS Infect. Dis. 1, 98-109. doi: 10.1021/id500022h

Whitley, R., Laughlin, A., Carson, S., Mitha, E., Tellier, G., Stich, M., et al. (2014). Single dose peramivir for the treatment of acute seasonal influenza: integrated analysis of efficacy and safety from two placebo-controlled trials. Antivir. Ther. 20, 709-719. doi: 10.3851/IMP2874

Wong, S.-S., and Webby, R. J. (2013). Traditional and new influenza vaccines. Clin. Microbiol. Rev. 26, 476-492. doi: 10.1128/CMR.00097-12

Wu, Y., Wu, Y., Tefsen, B., Shi, Y., and Gao, G. F. (2014). Bat-derived influenza-like viruses H17N10 and H18N11. Trends Microbiol. 22, 183-191. doi: 10.1016/j.tim.2014.01.010

Yamashita, M., Tomozawa, T., Kakuta, M., Tokumitsu, A., Nasu, H., and Kubo, S. (2009). CS-8958, a prodrug of the new neuraminidase inhibitor R-125489, shows long-acting anti-influenza virus activity. Antimicrob. Agents Chemother. 53, 186-192. doi: 10.1128/AAC.00333-08

Yang, X., Steukers, L., Forier, K., Xiong, R., Braeckmans, K., Van Reeth, K., et al. (2014). A beneficiary role for neuraminidase in influenza virus penetration through the respiratory mucus. PLOS ONE 9:e110026. doi: 10.1371/journal.pone.0110026

Yoo, J.-W., Choi, S.-H., Huh, J. W., Lim, C.-M., Koh, Y., and Hong, S.-B. (2015). Peramivir is as effective as oral oseltamivir in the treatment of severe seasonal influenza. J. Med. Virol. 87, 1649-1655. doi: 10.1002/jmv.24232

Yoshino, Y., Seo, K., Koga, I., Kitazawa, T., and Ota, Y. (2015). Clinical efficacy of peramivir in adult patients with seasonal influenza during the winter of 2012 in Japan. Clin. Respir. J. 9, 228-232. doi: 10.1111/crj.12129

Young, D., Fowler, C., and Bush, K. (2001). RWJ-270201 (BCX-1812): a novel neuraminidase inhibitor for influenza. Philos. Trans. R. Soc. Lond. B. Biol. Sci. 356, 1905-1913. doi: 10.1098/rstb.2001.1004

Yu, Y., Garg, S., Yu, P. A., Kim, H.-J., Patel, A., Merlin, T., et al. (2012). Peramivir use for treatment of hospitalized patients with influenza A (H1N1)pdm09 under emergency use authorization, october 2009-june 2010. Clin. Infect. Dis. 55, 8-15. doi: $10.1093 / \mathrm{cid} / \mathrm{cis} 352$

Yun, N. E., Linde, N. S., Zacks, M. A., Barr, I. G., Hurt, A. C., Smith, J. N., et al. (2008). Injectable peramivir mitigates disease and promotes survival in ferrets and mice infected with the highly virulent influenza virus, A/Vietnam/1203/04 (H5N1). Virology 374, 198-209. doi: 10.1016/j.virol.2007.12.029

Zaraket, H., Dapat, C., Ghanem, S., Ali, Z., Lteif, M., Kondo, H., et al. (2014). Characterization of human influenza viruses in lebanon during 20102011 and 2011-2012 post-pandemic seasons. Intervirology 57, 344-352. doi: $10.1159 / 000365758$

Zaraket, H., Saito, R., Wakim, R., Tabet, C., Medlej, F., Reda, M., et al. (2010). Antiviral drug susceptibilities of seasonal human influenza viruses in Lebanon, 2008-09 season. J. Med. Virol. 82, 1224-1228. doi: 10.1002/jmv.21795

Zhang, X., Song, Z., He, J., Yen, H.-L., Li, J., Zhu, Z., et al. (2014). Drug susceptibility profile and pathogenicity of H7N9 influenza virus (Anhuil lineage) with R292K substitution. Emerg. Microbes Infect. 3:e78. doi: 10.1038/emi.2014.80

Zhu, H., Lam, T. T.-Y., Smith, D. K., and Guan, Y. (2016). Emergence and development of H7N9 influenza viruses in China. Curr. Opin. Virol. 16, 106113. doi: 10.1016/j.coviro.2016.01.020

Zhu, L., Li, Y., Li, S., Li, H., Qiu, Z., Lee, C., et al. (2011). Inhibition of influenza A virus $(\mathrm{H} 1 \mathrm{~N} 1)$ fusion by benzenesulfonamide derivatives targeting viral hemagglutinin. PLoS ONE 6:e29120. doi: 10.1371/journal.pone.0029120

Conflict of Interest Statement: The authors declare that the research was conducted in the absence of any commercial or financial relationships that could be construed as a potential conflict of interest.

Copyright (c) 2016 Alame, Massaad and Zaraket. This is an open-access article distributed under the terms of the Creative Commons Attribution License (CC BY). The use, distribution or reproduction in other forums is permitted, provided the original author(s) or licensor are credited and that the original publication in this journal is cited, in accordance with accepted academic practice. No use, distribution or reproduction is permitted which does not comply with these terms. 